\title{
Article \\ Determination and Compensation of Non-Active Torques for Parallel HEV Using PMSM/IM Motor(s)
}

\author{
Branislav Dobrucky, Slavomir Kascak, Michal Frivaldsky *(D) and Michal Prazenica
}

check for updates

Citation: Dobrucky, B.; Kascak, S.; Frivaldsky, M.; Prazenica, M.

Determination and Compensation of Non-Active Torques for Parallel HEV Using PMSM/IM Motor(s). Energies 2021, 14, 2781. https://doi.org/ $10.3390 /$ en14102781

Academic Editor: Frede Blaabjerg

Received: 16 March 2021

Accepted: 7 May 2021

Published: 12 May 2021

Publisher's Note: MDPI stays neutral with regard to jurisdictional claims in published maps and institutional affiliations.

Copyright: (c) 2021 by the authors. Licensee MDPI, Basel, Switzerland. This article is an open access article distributed under the terms and conditions of the Creative Commons Attribution (CC BY) license (https:// creativecommons.org/licenses/by/ $4.0 /)$.
Faculty of Electrical Engineering and Information Technologies, University of Žilina, 01026 Zilina, Slovakia; branislav.dobrucky@feit.uniza.sk (B.D.); slavomir.kascak@feit.uniza.sk (S.K.); michal.prazenica@feit.uniza.sk (M.P.)

* Correspondence: michal.frivaldsky@feit.uniza.sk; Tel.: +421-41-513-1600

Abstract: The paper deals with the determination and compensation of non-active torques of parallel HEV using an auxiliary electrical PMSM or IM motor. The non-active oscillating torque generating by the ICE engine was estimated, and consequently, the compensating torque component of the current was determined. Based on real measured data, the four regimes of operation have been investigated: compensating non-active torques, parallel operation, regenerating for PMSM, and both parallel operations, together with compensation. Using of $\mathrm{p}-\mathrm{q}$ theory, the power of fundamental harmonic is presented by average values $P_{A V}, Q_{A V}$ of total power waveforms $p(t)$, and $q(t)$. Worked-out simulation results are used for sizing and dimensioning of PMSM machine, VSI inverter, and traction accumulator-battery. Circuit simulator Matlab/Simulink was used for all simulation experiments.

Keywords: HEV vehicle; parallel operation; active and non-active torque components; PMSM motor; ICE engine; torque mapping; FOC control

\section{Introduction}

Hybrid vehicles, mild or plug-in ones, play an important role in passenger urban traffic and/or in transport of HEV highway vehicles [1,2]. In parallel hybrids, an auxiliary electrical machine assists the ICE engine in delivering traction power, whereas their outputs are arranged in parallel. As a result of the operation of the ICE machine on its shaft, oscillating moments are generated, which cause both a ripple of the total torque and fluctuations in the speed of the device. To identifying those ripples is possible to use different methods [3-6]. In our case, however, it is possible to use our own auxiliary electric motor for identification. Most algorithms for minimizing torque ripple, whether due to non-sinusoidal induced voltage or cogging torque, assume that it is necessary, either online or offline, to identify ripple sources and their profile depending on the rotor position.

After identification, it is necessary to adjust the stator currents so that the added harmonic components compensate for the sources of torque ripple and thus achieve a smoother operation of the motor [7-9]. This has been achieved in the past by high bandwidth control $[10,11]$, repetitive control [12], or the application of simple artificial networks [3,4]. Assuming a parallel HEV vehicle, we will be focused on an auxiliary electrical motor which can serve to increase traction power and to compensate for non-active oscillating torque generated mainly by the ICE engine. Other works $[13,14]$ have focused on a description of the noise vibration characteristics and corresponding suppression methods of HEVs or/and exploring the effect of a dual-mass flywheel on the torsional vibration characteristics of a power-split hybrid powertrain, respectively.

Generally, there are two groups of the source of oscillating torques and thus also ripple of the rotating speed of the electric motor

- internal ones,

- external ones. 
Among the internal sources, from the point of view of auxiliary electric machines, we can introduce these as cogging torque, the shape of back emf, mechanical and electrical failures caused by construction, and as the shape of the current, dead-time, etc. Among the external sources, from the point of view of HEV, there are torques caused by the ICE engine, gears, mechanical resonances, etc. In this paper, mainly external sources of the oscillating torques will be investigated.

Unlike the aforementioned previous works, the paper describes, besides the compensation of non-active oscillating torques, an investigation of all functional procedures needed:

- estimation external torques by auxiliary PMSM/IM motor;

- compensation of non-active oscillating ones;

- power circumstances calculation;

- dimensioning needs of the auxiliary PMSM motor, VSI converter, and accu-battery.

The first task in this investigation is the identification and/or estimation of these non-active oscillating torques. The second, is the compensation of identified oscillating torque using an auxiliary electric motor (PMSM/IM). The next one, parallel cooperation of ICE and e-motor and compensation torque and speed ripple can be provided. The main task is to determine the size of the auxiliary electric motor, which would work in parallel with the ICE machine and at the same time compensate for torque and speed ripple. The instantaneous reactive power method $[15,16]$ is used to determine the power components on input motor terminal although it is also possible to use more accurate methods to calculate motor losses [17]. Based on the received result we can provide a sizing and dimensioning of the PMSM motor, VSI converter, and Accu-battery.

\section{Identification of the Total Active Torques of Traction Power Transmission}

One possibility for identification of the load torque is the use of the auxiliary motor itself. Unlikely internal sources, when we investigate the motor in no-load operation $[9,18]$, the external sources should be investigated under full load operation or in the entire region of the load and speed, respectively.

An example of the oscillating torque course and corresponding speed is shown in Figure 1.
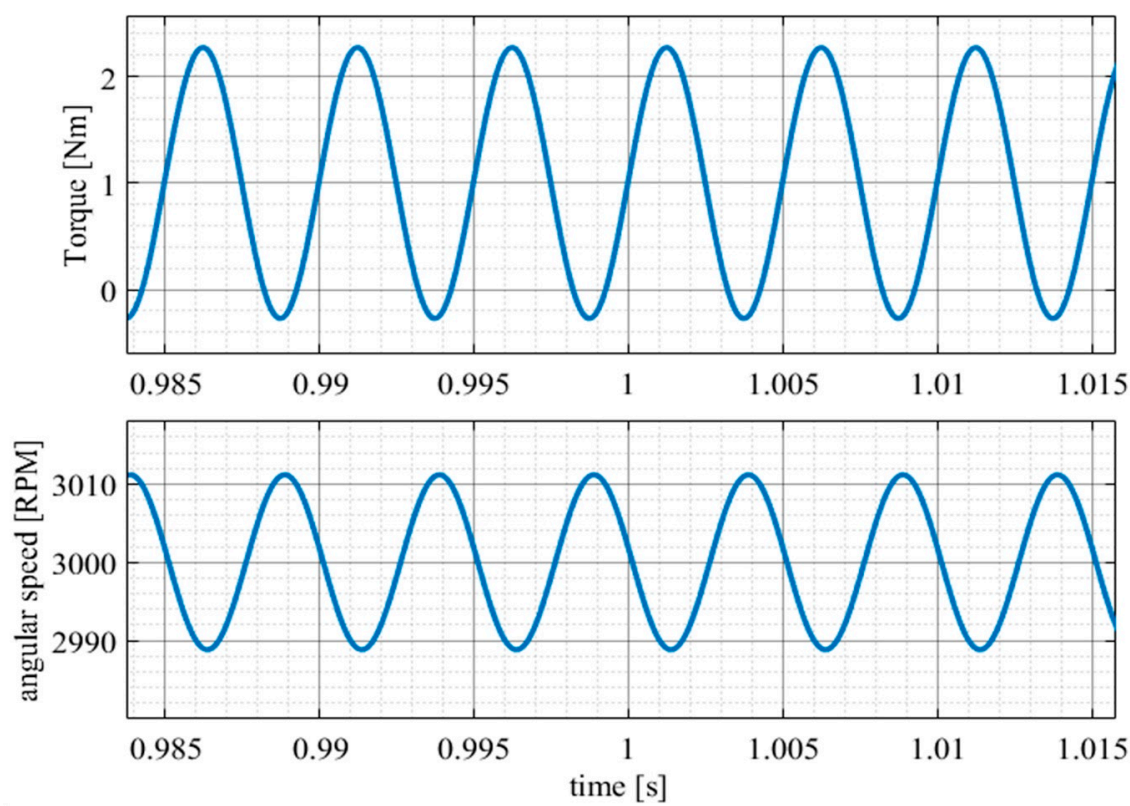

Figure 1. Example of the torque and corresponding speed: torque (top); speed ripple (bottom).

The torque consists of an active mean value component $T_{\mathrm{av}}$ and non-active oscillating components $T_{\mathrm{osc}}$. The total torque course may change depending on rotating speed and 
loading (loaded torque). Therefore, it is necessary to map these changes and create a two-dimensional map at the whole range speed and load (Figure 2). This all can be done using measuring apparatus placed on the shaft of the HEV engine, but it is not a simple matter, and is, in fact, a rather complex one [19].

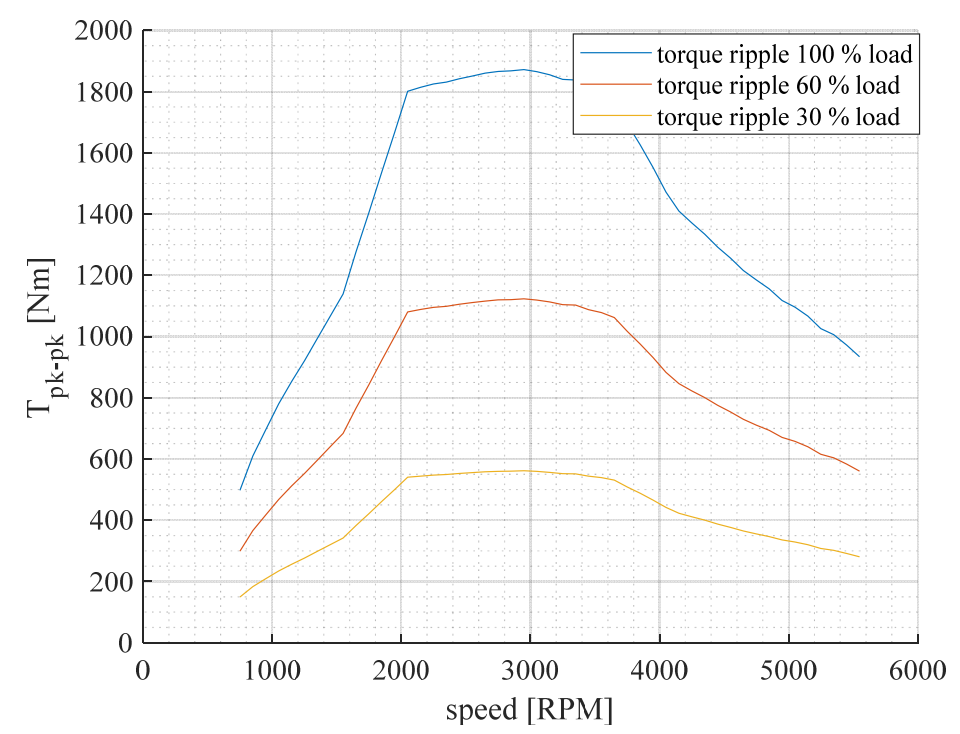

Figure 2. Mapping oscillating torque depending on rotating speed and loading $100-60-30 \%$ without damper.

Figure 2 shows the extraction of the torque ripple $T_{p k-p k}$ from the measured torques of the internal combustion engine at different loads.

Another way how to get these courses is to use an auxiliary traction electrical motor. This can be either synchronous or induction (asynchronous) one. From measured and estimated currents, rotating speed and its derivative we can reconstruct these courses. Both solutions will be demonstrated.

\subsection{Torque Estimation Using Embedded Auxiliary Motor}

Generally, the motor torque Equation (1) applies

$$
t_{\text {elmg }}=T_{l}+t_{a c c}=T_{l}+J_{m} \frac{\mathrm{d} \omega_{m}}{\mathrm{~d} t}
$$

where in the load moment $T_{l}$ can have both unidirectional (constant) and oscillating components and includes the friction moment in the bearings of the machine (rolling and viscous friction).

The additional acceleration torque $t_{a c c}$ is required to start the machine at the required speed at a given load torque. The internal electromagnetic torque of the electric motor depends on the machine parameters and is a function of the motor current, as well as the speed and position of the rotor (for AC machines). The load moment is usually given as in Equation (2);

$$
t_{l}=T_{a v}+t_{o s c}+t_{f r i}
$$

however, if we do not know it or it may change, it is possible to determine its size by measuring with a dynamometer with a torque sensor.

Another method of determination is its reconstruction using the measured values of the motor (current, speed) and the given parameters of the machine. From Equation (1) we express the moment of the load as an unknown required quantity, i.e., the reconstructed estimated moment is shown in Equation (3).

$$
t_{l, e s t}=t_{e l m g}-J_{m} \frac{\mathrm{d} \omega_{m}}{\mathrm{~d} t}
$$


where the internal electromagnetic moment is expressed by means of the measured current(s) and, the measured motor speed, Equation (4);

$$
t_{\text {elmg }}=f\left(i_{m}, \omega_{m}\right)
$$

The reconstructed torque will therefore be a function of the motor currents, the motor speed and their derivative, Equation (5).

$$
t_{l, e s t}=f\left(i_{m}, \omega_{m}, \frac{\mathrm{d} \omega_{m}}{\mathrm{~d} t}\right)
$$

Any other required quantities, such as the current and the position of the rotor, can be estimated from these measured quantities. Of course, for each type of motor, the equation for the electromagnetic torque will have a different shape and the relationship for the reconstructed load torque.

\subsection{Estimation of Electromagnetic Torque for PMSM Synchronous Motor with Permanent Magnets}

PMSM model in $d, q$ coordinates is described in [20-22], while here we introduce the main equations required for further modeling. The voltages in $d, q$ coordinates are defined by (6) and (7);

$$
\begin{gathered}
u_{d}=R_{s} i_{d}+L_{d} \frac{\mathrm{d} i_{d}}{\mathrm{~d} t}-\omega L_{q} i_{q} \\
u_{q}=R_{s} i_{q}+L_{q} \frac{\mathrm{d} i_{q}}{\mathrm{~d} t}+\omega\left(L_{d} i_{d}+\Psi_{P M}\right)
\end{gathered}
$$

The internal electromagnetic torque and mechanical quantities are given by (8)-(9).

$$
\begin{gathered}
t_{\text {elmg }}=\frac{3}{2} P p\left(i_{d} \cdot i_{q} *\left(L_{d}-L_{q}\right)+\Psi_{P M} i_{q}\right. \\
\frac{\mathrm{d} \omega_{m}}{\mathrm{~d} t}=\frac{P p}{J_{m}}\left(t_{\text {elmg }}-T_{l}\right) \quad \vartheta_{m}=\int_{0}^{\infty} \omega_{m} d t \quad \frac{\mathrm{d} \vartheta_{m}}{\mathrm{~d} t}=\omega_{m}
\end{gathered}
$$

Load torque could be specified as follows:

$$
t_{l}=T_{a v}+t_{o s c}+t_{f r i}
$$

Estimated reconstructed torque will be

$$
t_{l, e s t}=t_{\text {elmg }}-J_{m} \frac{\mathrm{d} \omega_{m}}{\mathrm{~d} t}=-\frac{J_{m}}{\tau_{m e c h}} \omega_{m}+\frac{3}{2} P p\left(i_{d} \cdot i_{q} *\left(L_{d}-L_{q}\right)+\Psi_{P M} i_{q}-J_{m} \frac{\mathrm{d} \omega_{m}}{\mathrm{~d} t}\right.
$$

where the friction component of the load moment was expressed explicitly, together with the internal electromagnetic $t_{\text {elmg }}$ and the acceleration $t_{a c c}$ of the motor torque. The components of the motor stator current vector-the quantities $i_{s \alpha}, i_{s \beta}$, Equations (12a) and $(12 \mathrm{~b})$, are determined, resp. measured indirectly, from measured currents $i_{s \alpha}, i_{s \beta}$ :

$$
\begin{gathered}
i_{s \alpha}=i_{a} \\
i_{s \beta}=\frac{1}{\sqrt{3}}\left(i_{s b}-i_{s c}\right)=\frac{1}{\sqrt{3}}\left(2 i_{s b}+i_{s \alpha}\right)
\end{gathered}
$$

The $d q$ component of the stator current $i_{s d}$ and $i_{s q}$ can be calculated using transformation from $\alpha \beta$ to $d q$ frame. 
The mechanical angular velocity $\omega_{m}$ and the position of the rotor $\vartheta$ are directly measurable quantities, also stator currents $i_{a}, i_{b}$. The rotor position $\vartheta$ can also be calculated (estimated) as a time integral of the rotational mechanical angular velocity of the motor $\omega_{m}$.

$$
\vartheta=\int_{0}^{\infty} \omega_{m} \mathrm{~d} t
$$

Using a PMSM motor is the easier solution (due to PMSM rotor), as the induction motor IM is characterized by greater moment of inertia helping to reduce speed ripple, but we need to estimate also rotor currents.

\subsection{Estimation of Electromagnetic Torque for Cylinder Asynchronous Motor with} Squirrel-Cage Armature

Internal electromagnetic torque of the induction motor (IM) is defined as follows:

$$
t_{\text {elmg }}=\frac{3}{2} P p \frac{L_{m}}{J_{m}}\left(i_{r \alpha} \cdot i_{s \beta}-i_{s \alpha} \cdot i_{r \beta}\right)
$$

where $i_{s \alpha}, i_{s \beta}$ are alfa, beta stator currents and $i_{r \alpha}, i_{r \beta}$ rotor currents.

Load torque could be defined as:

$$
t_{l}=T_{a v}+t_{o s c}+t_{f r i}
$$

while estimated torque is as follows:

$$
t_{l, e s t}=t_{\text {elmg }}-J_{m} \frac{\mathrm{d} \omega_{m}}{\mathrm{~d} t}=\frac{3}{2} P p \frac{L_{m}}{J_{m}}\left(i_{r \alpha} \cdot i_{s \beta}-i_{s \alpha} \cdot i_{r \beta}\right)-J_{m} \frac{\mathrm{d} \omega_{m}}{\mathrm{~d} t}
$$

where in the stator components of the current vector $i_{s \alpha}, i_{s \beta}$ are determined, resp. measured indirectly, from measured stator currents $i_{s \alpha}, i_{s \beta}$, Equations (16a) and (16b), and recalculated using Clarke transform:

$$
\begin{gathered}
i_{s \alpha}=i_{s a} \\
i_{s \beta}=\frac{1}{\sqrt{3}}\left(i_{s b}-i_{s c}\right)=\frac{1}{\sqrt{3}}\left(2 i_{s b}+i_{s a}\right)
\end{gathered}
$$

Rotor currents $i_{r \alpha}, i_{r \beta}$ are calculated according to the relations from the IM motor model:

$$
\begin{aligned}
& i_{r \alpha}=i_{r \alpha}+\mathrm{d} T \cdot K_{r}\left(R_{s} \frac{L_{m}}{L_{r}} i_{s \alpha}-R_{r} i_{r \alpha}-\omega_{m}\left(L_{m} i_{s \beta}+L_{r} i_{r \beta}\right)-\frac{L_{m}}{L_{s}} U_{\alpha}\right) \\
& i_{r \beta}=i_{r \beta}+\mathrm{d} T \cdot K_{r}\left(R_{s} \frac{L_{m}}{L_{r}} i_{s \beta}-R_{r} i_{r \beta}+\omega_{m}\left(L_{m} i_{s \alpha}+L_{r} i_{r \alpha}\right)-\frac{L_{m}}{L_{s}} U_{\beta}\right)
\end{aligned}
$$

where $K_{r}$ is the rotor constant (see Blondel's coefficients)

$$
K_{r}=\frac{L_{s}}{L_{s} L_{r}-L_{m}^{2}}
$$

and the components of the stator voltage vector $U_{\alpha}, U_{\beta}$ can be measured, similarly to the currents $i_{s \alpha}, i_{s \beta}$, or the reference voltage from FOC control can be used.

The quantity $\omega_{m}$ is being measured, while the position of the rotor $\vartheta$ can be calculated (estimated) as a time integral of the rotational mechanical angular velocity $\omega_{m}$ :

$$
\vartheta=\int_{0}^{\infty} \omega_{m} \mathrm{~d} t \text {, thus } \vartheta=\vartheta_{0}+\mathrm{d} T \cdot \omega_{m}
$$




\section{Model Development within Matlab Environment}

In all cases of program implementation of PMSM and IM motor, the speed derivative, resp. mechanical angular velocity of the engine is replaced by its first derivation:

$$
\frac{\mathrm{d} \omega_{m}}{\mathrm{~d} t} \approx \frac{\omega_{m}(k+1)-\omega_{m}(k)}{\Delta T}
$$

wherein it is necessary to remember the value of revolutions from the previous step $\omega_{m}(k)$ and calculate the new value $\omega_{m}(k+1)$ according to the appropriate relation from the discrete mathematical model of the machine. As an example, we can follow the calculation of the reconstructed torque of the PMSM motor (Figure 3). The directly measurable quantities of PMSM are $\omega_{m}, i_{a}, i_{b}$, calculated quantities are $i_{d}, i_{q}, \vartheta, \omega_{m}(k+1), \omega_{m}(k)$. The principle waveforms of $\omega_{m}, i_{a}, t_{l}$ and $t_{l, \text { est }}$ are shown below.
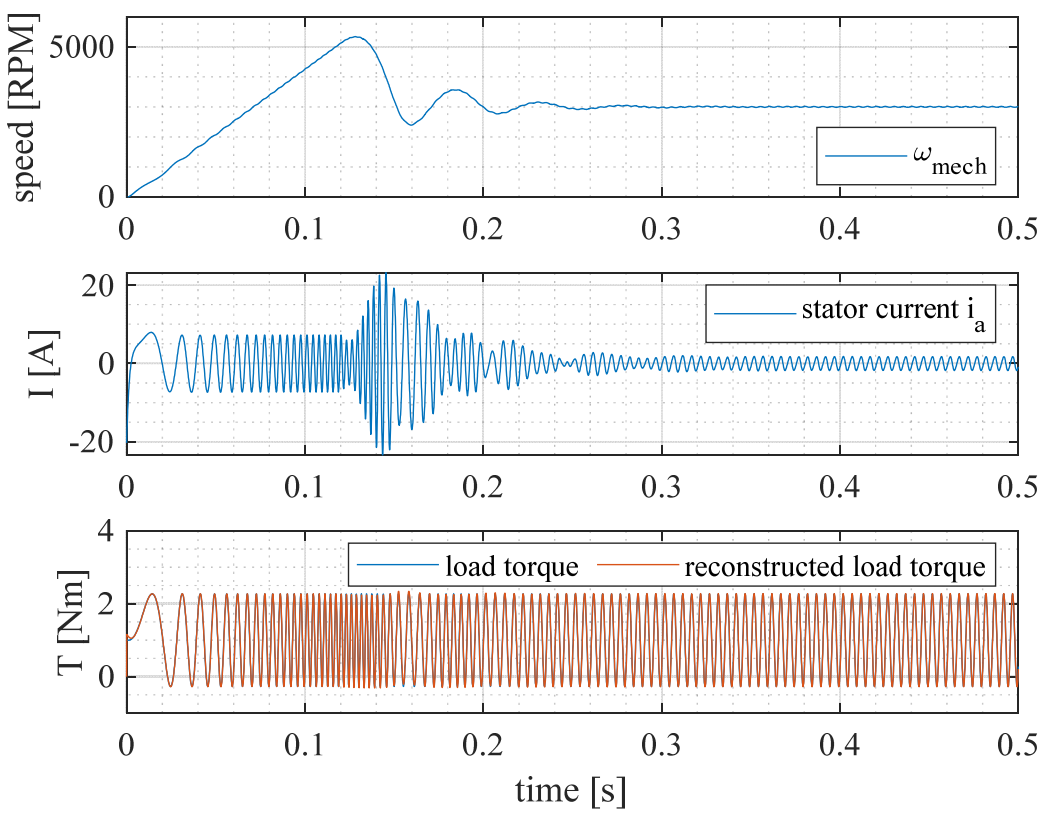

Figure 3. Speed, current, load torque, and reconstructed load torque.

The model development of IM estimation in Matlab environment is like PMSM one.

\subsection{Reconstruction of Oscillating Torque}

After estimation of the total load moment $t_{l, e s t}$, it is necessary to determine which part of it represents the oscillating moment $t_{o s c}$. From the equation for the load torque, we get:

$$
t_{o s c}=t_{l, e s t}-T_{a v}-t_{f r i}
$$

where terms $T_{a v}, t_{f r i}$ are known.

To evaluate this waveform $t_{o s c}$ as a periodic time function $f(t)$, we can use Fourier analysis to obtain the magnitudes of the amplitudes of the individual harmonic components. Equations apply to Fourier coefficients:

$$
c_{k}=\frac{2}{T} \int_{0}^{T} t_{o s c}(t) \cdot e^{j k \omega t} \mathrm{~d} t
$$

resp. $a_{k}=\frac{2}{T} \int_{0}^{T} t_{\text {osc }}(t) \cdot \cos (k \omega t) \mathrm{d} t, b_{k}=\frac{2}{T} \int_{0}^{T} t_{\text {osc }}(t) \cdot \sin (k \omega t) \mathrm{d} t ; c_{k}=\sqrt{a_{k}{ }^{2}+b_{k}{ }^{2}}$, where $c_{k}$ is the amplitude and $k \omega t$ is the angular frequency $\left(f_{k}=\frac{k \omega}{2 \pi}\right)$ of the corresponding $k$-th harmonic component. 
The largest harmonic components can then be compensated by introducing them into the reference value of the torque regulator, with the opposite phase $[17,23]$. To determine the total course of the oscillating moment (with all harmonic components), we need to calculate the mean value $T_{a v}$ using the relation from Fourier analysis

$$
T_{a v}=\frac{1}{T} \int_{0}^{T} t_{l, e s t}(t) \mathrm{d} t
$$

and subtracting this value from the total reconstructed load torque $t_{l, e s t}$ in Equations (11) and (17).

In order not to have to calculate the integral for the whole time period, it is advantageous to use the moving average method (MAM) with shifting the integration window off width $T$ with the appropriate integration step $\Delta T$, whereby the mean value of the load moment $T_{a v}$ is determined continuously in each calculation step $k \Delta T$-if we use the on-line method.

\subsection{Machine Power Calculation}

Estimated total torque on a shaft using PMSM motor will be considered as a torque sensor. The total torque measured and calculated on the shaft without compensation is given in Figure 4.

$$
i_{q}(\vartheta)=\frac{2}{3} \frac{T_{t o t}(\vartheta)}{P p \Psi_{P M}}=\frac{2}{3} \frac{T_{a v}(\vartheta)+t_{o s c}(\vartheta)}{P p \Psi_{P M}}
$$

where $i_{q}$ calculated is given by

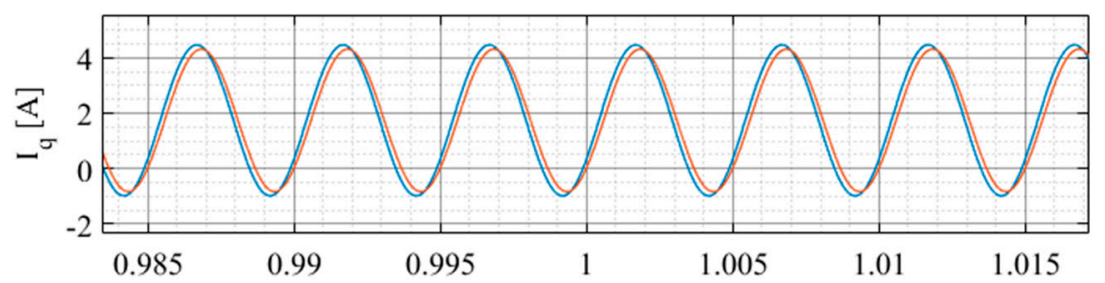

(a)

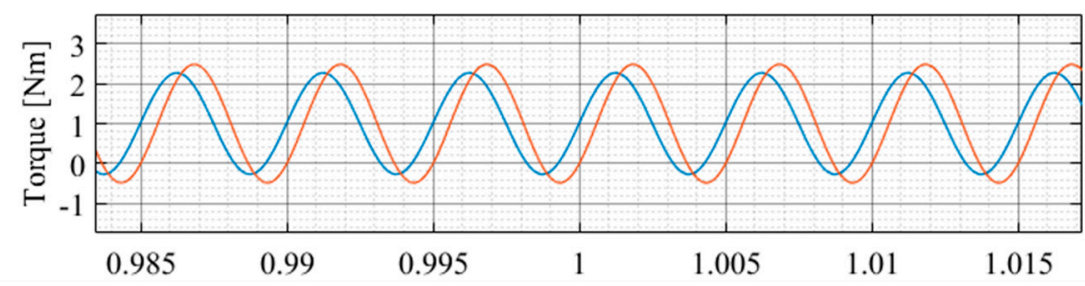

(b)

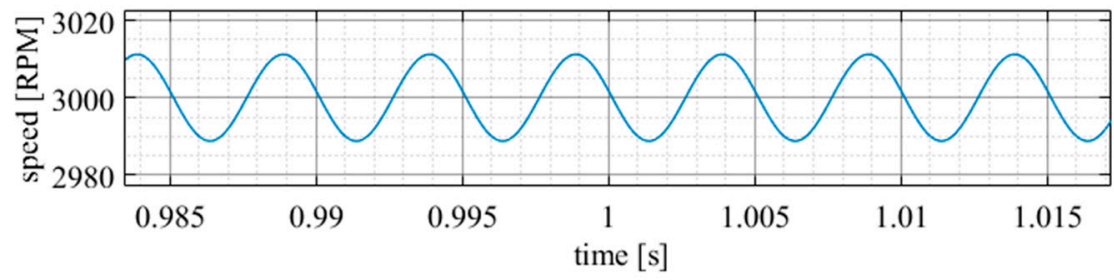

(c)

Figure 4. Total torque measured and electromagnetic one without compensation. (a) $i_{q}$ measured (orange) and $i_{q}$ generated by speed controller (blue); (b) load torque course (blue) and electromagnetic one (orange); (c) rotating angular speed.

Regarding the terms of increasing the motor power, its value should be increased by the reactive part needed for compensating of oscillating torque, whose average (mean) value is zero. The total apparent power of the motor taken from the main 3-phase network will be:

$$
S=U_{a, r m s} I_{a, r m s}+U_{b, r m s} I_{b, r m s}+U_{c, r m s} I_{c, r m s}=\frac{3}{2}\left(U_{\alpha, r m s} I_{\alpha, r m s}+U_{\beta, r m s} I_{\beta, r m s}\right)
$$


or

$$
S_{(a v)}=\sqrt{P_{1(a v)}^{2}+Q^{2} \Sigma(a v)+D^{2} \Sigma(a v)}
$$

Since the active power $P_{1(a v)}$ is clearly given as:

$$
P=\frac{T_{a v, n o m}}{\omega_{m}}
$$

to know the reactive one, we need to determine phase shift $\varphi_{1}$

$$
Q_{1(a v)}=U_{1 r m s} I_{1 r m s} \sin \varphi_{1} Q_{\Sigma(a v)}=U_{\Sigma, r m s} I_{\Sigma, r m s} \sin \varphi_{v}
$$

therefore, we can use the instantaneous $p \_q$ reactive power theory $[13,14]$.

Instantaneous power $p_{-} q$ components in alfa, beta coordinate system is defined as in (31). We left alfa, beta to be not interfered with the $d, q$ control system:

$$
\left[\begin{array}{l}
p \\
q
\end{array}\right]=\frac{3}{2}\left[\begin{array}{cc}
u_{\alpha} & u_{\beta} \\
-u_{\beta} & u_{\alpha}
\end{array}\right]\left[\begin{array}{l}
i_{\alpha} \\
i_{\beta}
\end{array}\right]=\left[\begin{array}{cc}
P_{a v}+ & p_{a c} \\
Q_{a v}+ & q_{a c}
\end{array}\right]
$$

where

$$
P_{a v}=\frac{1}{T} \int_{0}^{T}\left(u_{\alpha} i_{\alpha}+u_{\beta} i_{\beta}\right) d t ; \quad Q_{a v}=\frac{1}{T} \int_{0}^{T}\left(u_{\alpha} i_{\beta}-u_{\beta} i_{\beta}\right) d t
$$

while required phase shift $\varphi_{1}$ of fundamental harmonic component is:

$$
\varphi_{1}=\operatorname{atan} \frac{Q_{a v}}{P_{a v}}
$$

whereby $P_{a v}$ and $Q_{a v}$ mean values are defined by (34).

$$
P_{a v}=U_{1 r m s} I_{1 r m s} \cos \varphi_{1} ; \quad Q_{a v}=U_{1 r m s} I_{1 r m s} \sin \varphi_{1}
$$

and $p_{a c}, q_{a c}$ components represent the reactive power of higher harmonics.

Knowing $S_{a v}, P_{a v}, Q_{a v}$, we are able to determine distortion power using (35).

$$
D_{a v}=U_{1 r m s} \sqrt{\sum I_{k, r m s}^{2}}=\sqrt{S_{a v}^{2}-P_{a v}^{2}-Q_{a v}^{2}}
$$

where

$$
S_{a v}=\frac{3}{2}\left(U_{\alpha r m s} I_{\alpha r m s}+U_{\beta r m s} I_{\beta r m s}\right)
$$

and knowing $p_{a c}, q_{a c}$

$$
\left[\begin{array}{l}
p_{a c} \\
q_{a c}
\end{array}\right]=\left[\begin{array}{ll}
p- & P_{a v} \\
q- & Q_{a v}
\end{array}\right]
$$

Then distortion power is defined as follows:

$$
D_{a v}=U_{1 r m s} I_{\sum r m s}=U_{1 r m s} \sqrt{I_{\sum p, r m s}^{2}+I_{\sum q, r m s}^{2}}=\sqrt{p_{a c, r m s}^{2}+q_{a c, r m s}^{2}}
$$

and we can also determine the total apparent power using (39)

$$
S_{a v}=\sqrt{P_{a v}^{2}+Q_{a v}^{2}+D_{a v}^{2}}
$$

\section{Compensation of the Oscillating Torque and Speed Ripple Considering One Independent PMSM Motor}

Based on the previous analysis and calculations regarding reconstructed oscillating torque, it is possible to compensate the load oscillating torque by introducing it within the torque controller reference value with the opposite phase position, i.e., negative sense $[17,18]$. Unfortunately, the identification and compensation of oscillating torque is 
not possible at the same time by the same motor. The main principle of the used method consists of the compensation technique given in Figure 5.

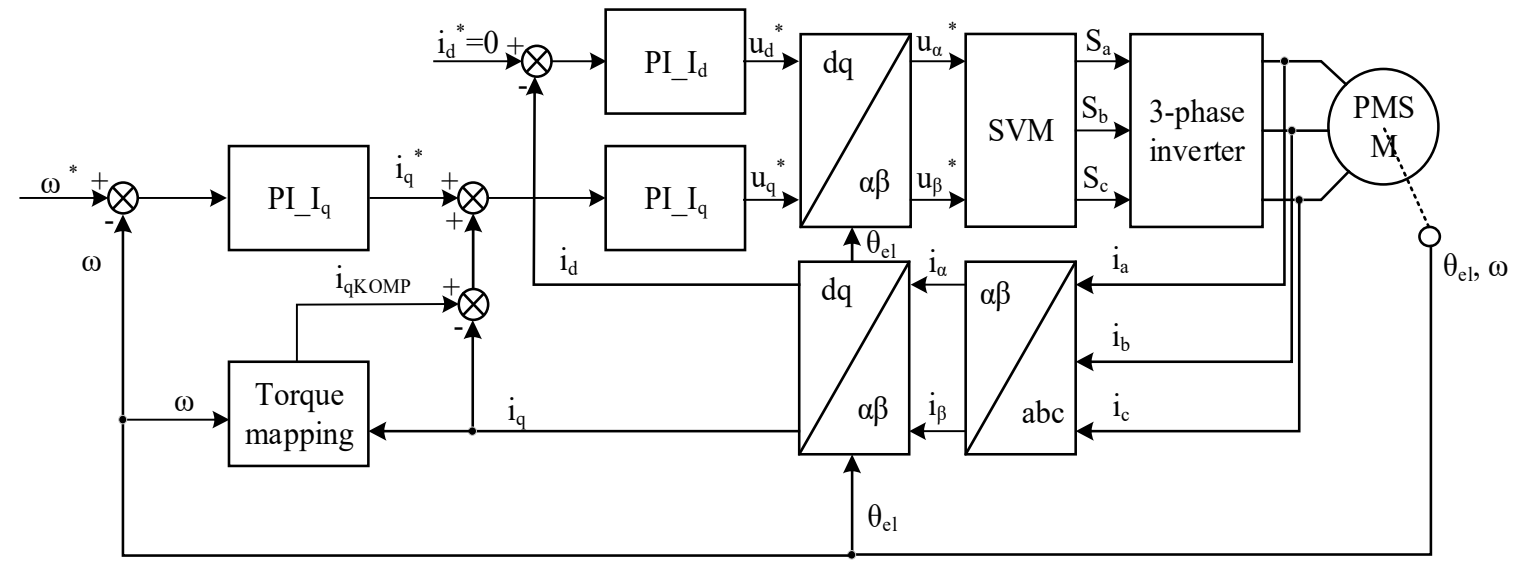

Figure 5. Block scheme of PMSM motor under FOC with oscillating torque compensation.

In this figure the compensating current $i_{q, \text { comp }}(\vartheta)$ is estimated using the $i_{q}$ which is defined by the next equation:

$$
i_{q}(\vartheta)=\frac{2}{3} \frac{T_{t o t}(\vartheta)}{P p \Psi_{P M}}=\frac{2}{3} \frac{T_{a v}(\vartheta)+t_{o s c}(\vartheta)}{P p \Psi_{P M}}
$$

while it is a function dependent on speed and load of the motor generating torque (ICE engine and/or PMSM).

Simulation results using the Matlab/Simulink environment [24] are shown in Figure 6, in which it depicts the total torque measured and calculated on the shaft with compensation.

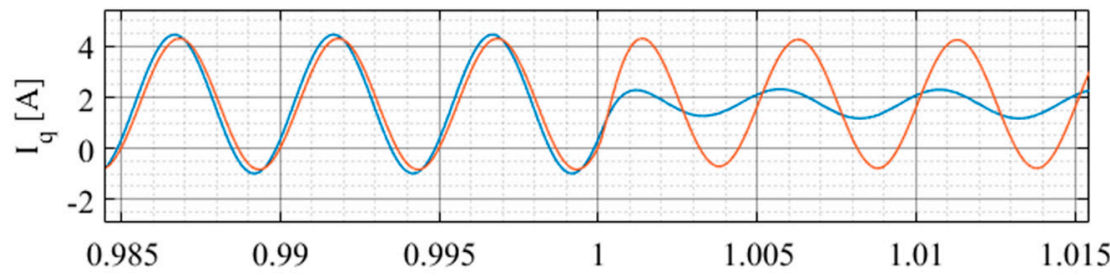

(a)

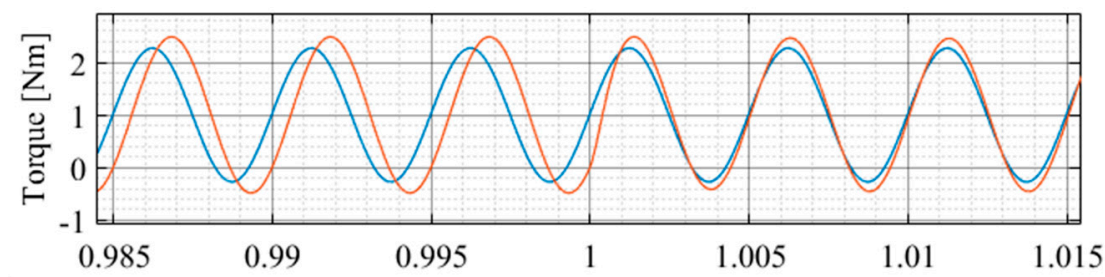

(b)

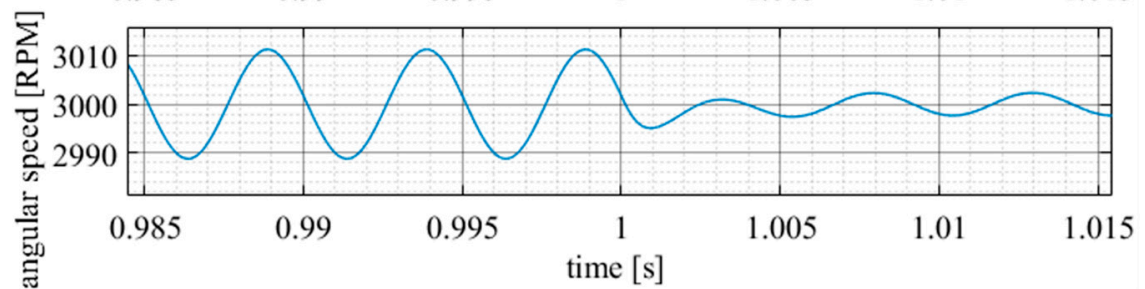

(c)

Figure 6. Total torque measured and electromagnetic one with compensation $t_{\text {osc. }}$ (a) $i_{q}$ measured (orange) and $i_{q}$ generated by speed controller (blue); (b) load torque course (blue) and electromagnetic one (orange); (c) rotating angular speed.

Resulting power components $P_{a v}, Q_{a v}$, and $p_{a c}, q_{a c}$ are given in Figures 7-9. Based on the received result, we can provide a sizing and dimensioning of the PMSM motor. 

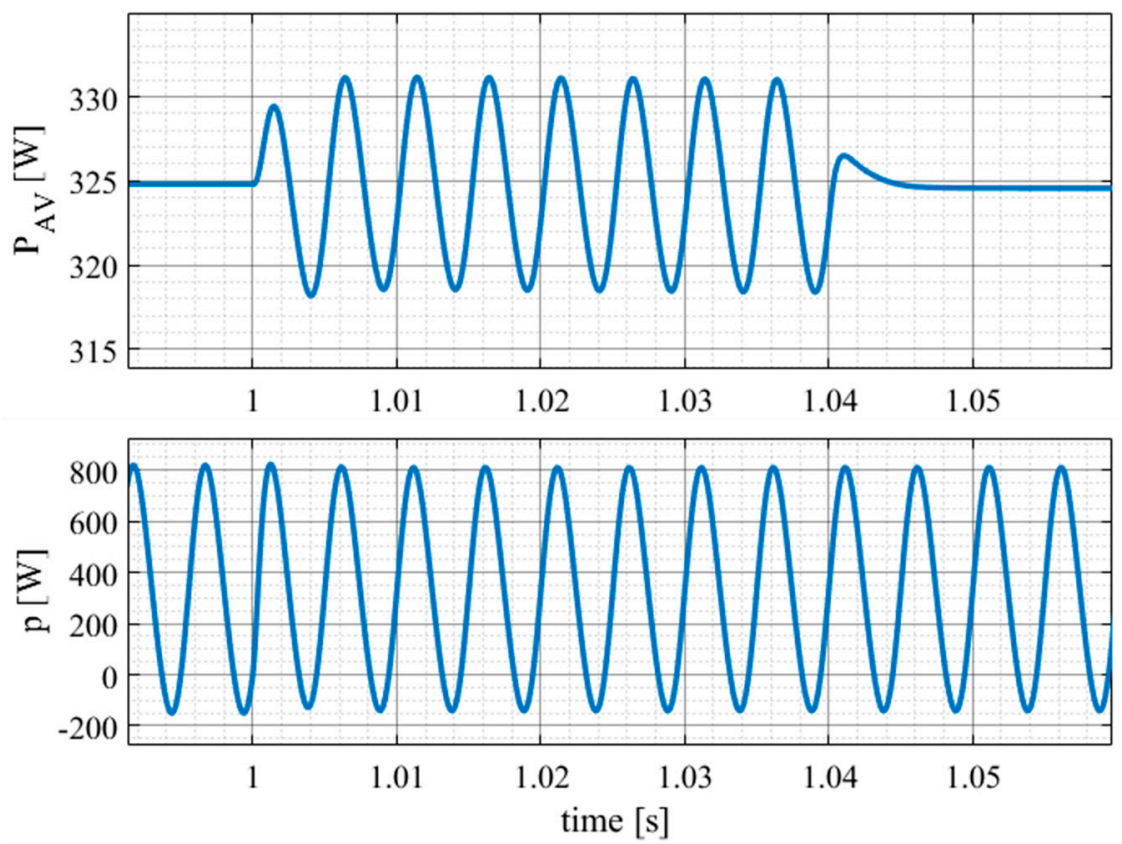

Figure 7. Time waveforms of $P_{a v}$ and $p$-case of compensation (top) $P_{a v}$ during compensation (top); (bottom) $p$ during compensation (stays constant).
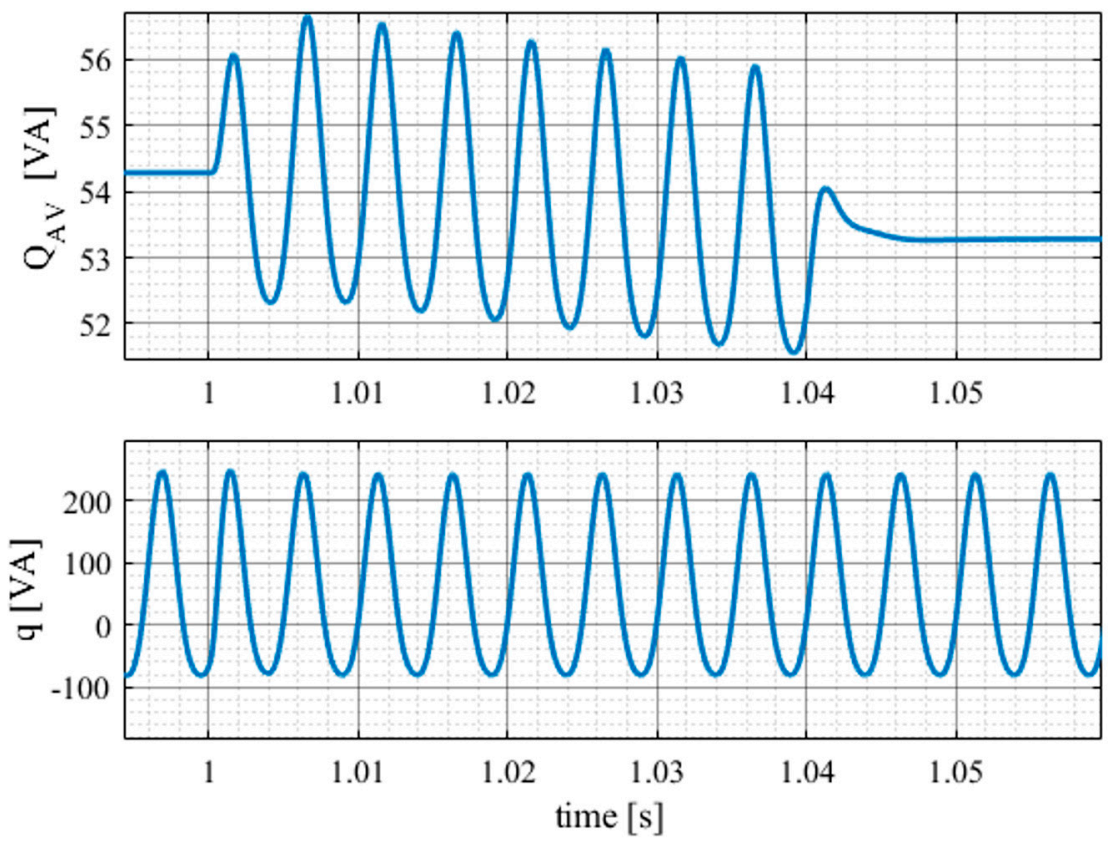

Figure 8. Time waveforms of $Q_{a v}$ and $q$-case of compensation (top) $Q_{a v}$ during compensation (top), (bottom) $q$ during compensation (stays constant). 

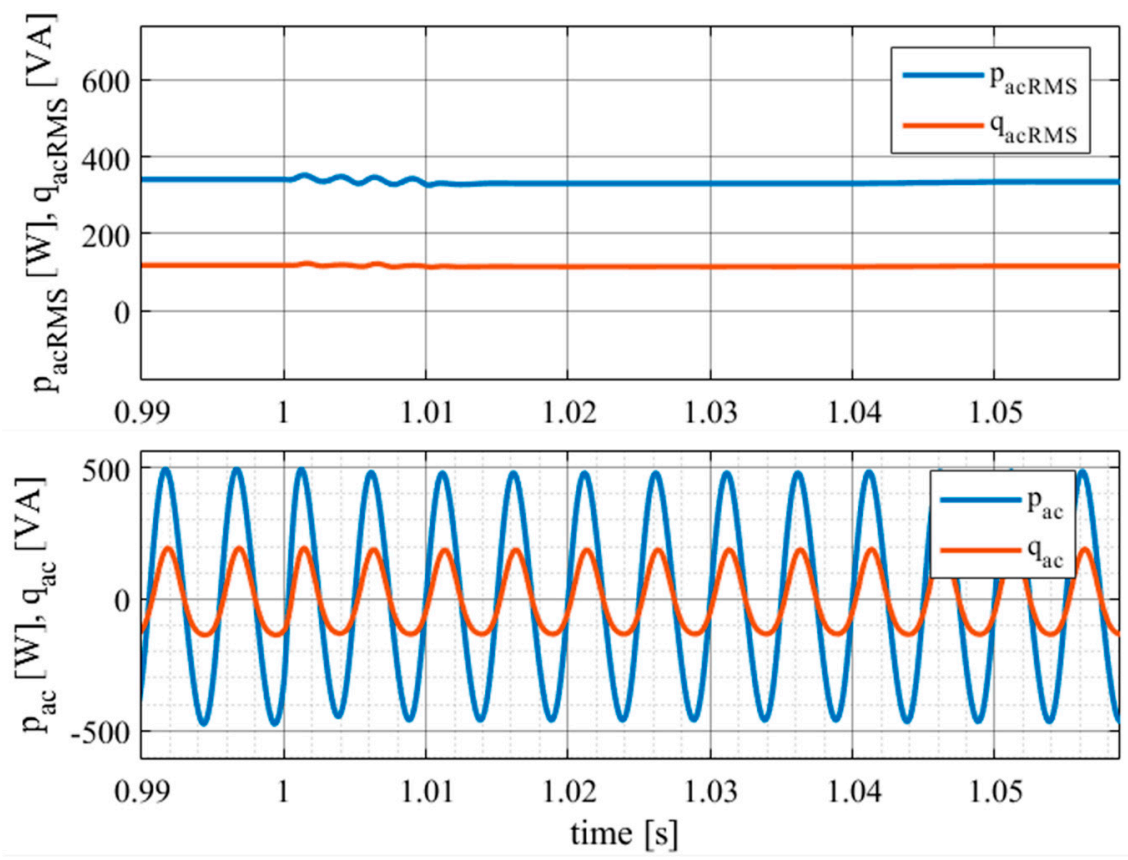

Figure 9. Time waveforms of $p_{a c, \prime} q_{a c}$ and $P_{a c, r m s}, Q_{a c, r m s}$ - case of compensating.

The compensation starts at $1 \mathrm{~s}$. It is interesting that under compensation, the oscillating (AC) components $p_{a c}, q_{a c}$ of $p, q$ stay unchanged, but DC components $P_{a v}, Q_{a v}$ are changing.

\section{Application in Parallel HEV Powertrain}

Unlike the above description, the ICE engine and auxiliary electric motor (PMSM) cooperate together, while the electric motor can simultaneously compensate for oscillating torque generated by ICE and also secure the transfer of traction power. Regarding the compensation, the approach has been described above.

Firstly, we need to know the measured total torque on the joint shaft of ICE and PMSM. One of the real examples is shown in Figure 10a,b [23].

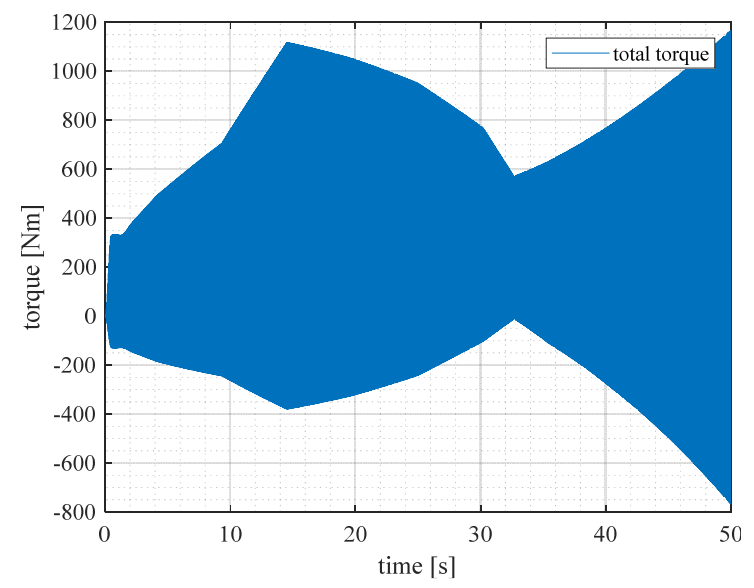

(a)

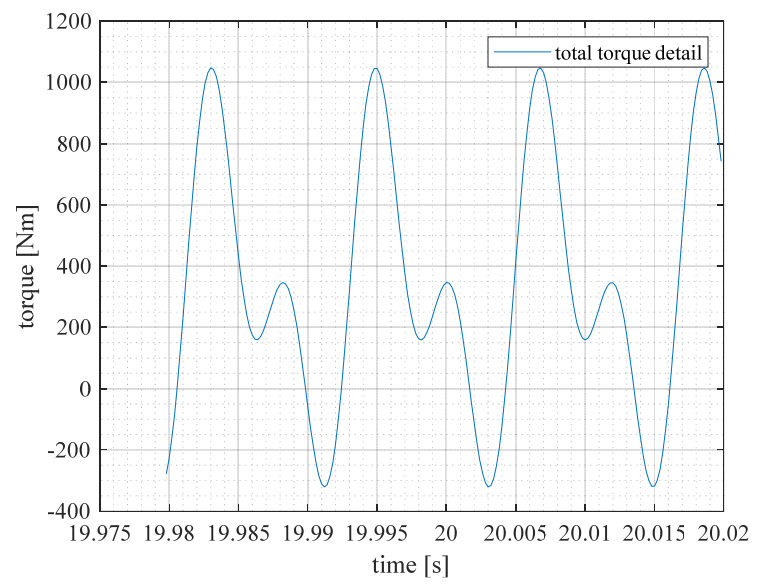

(b)

Figure 10. Total torque course measured on the shaft of ICE (a) and its detail during one testing cycle of the engine (b).

As mentioned, it consists of the mean torque value and the oscillating parts of the torque. So, we need to calculate them using Fourier analysis. Knowing the mean value and oscillating part, we can begin to simulate compensation action using the model from 
Figure 5. Results of Fourier analysis are shown in Figure 11. Mean value of the torque and rotating speed of the ICE during one testing cycle of the engine is shown in Figure 12.

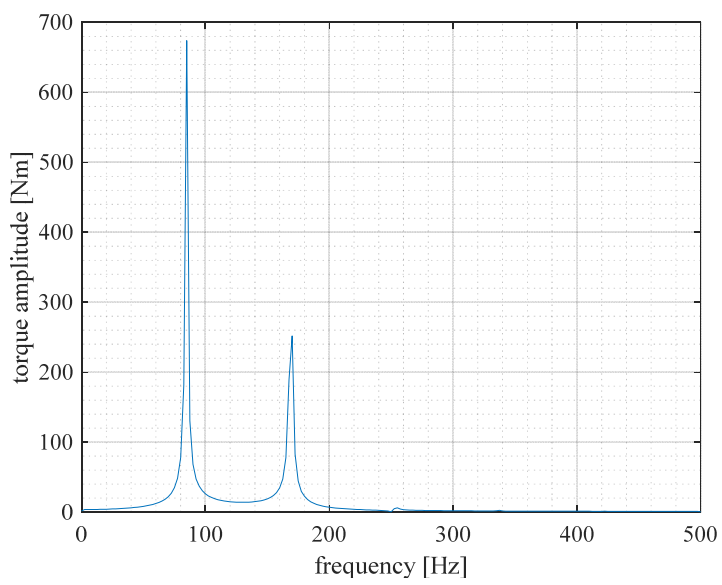

Figure 11. Dominant harmonics of ICE torque and its Fourier analysis results.

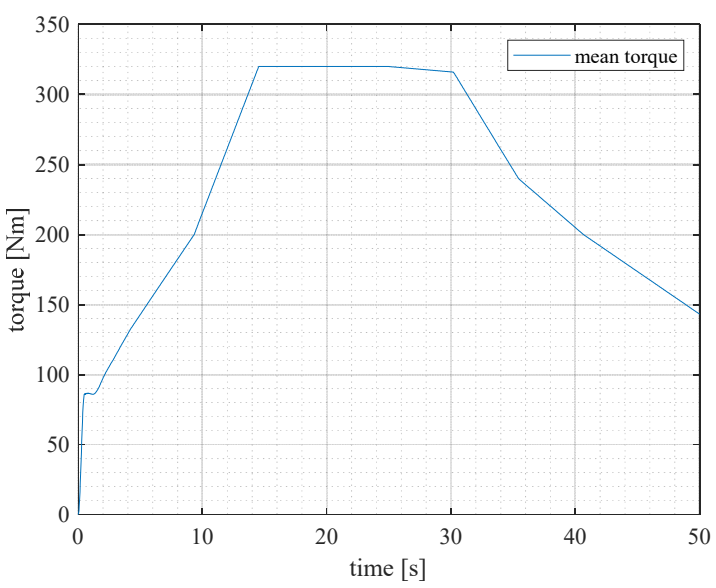

(a)

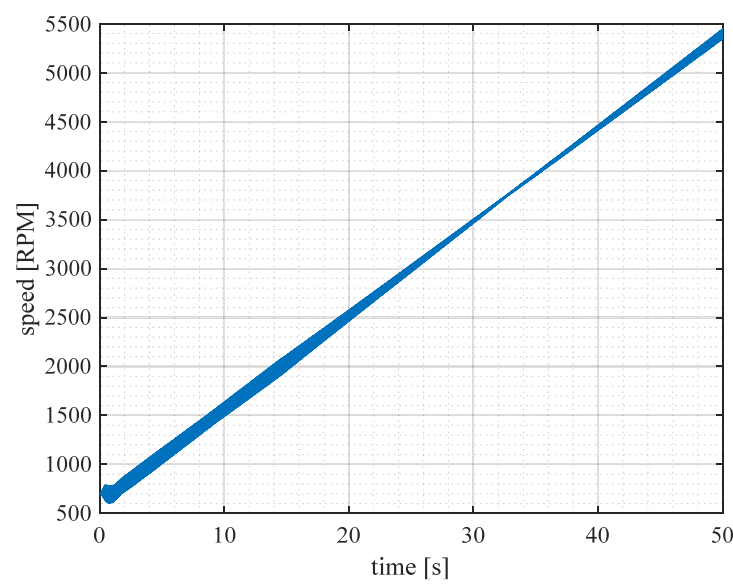

(b)

Figure 12. Mean value of the torque (a) and rotating speed of the ICE (b) during one testing cycle of the engine.

Since we did not have the parameters of the internal combustion engine, only the measured torque characteristics, we used the replacement of ICE by an electric machine. Then for further simulation analyses, the ICE engine was substituted by the electrical machine. We have used synchronous PM machine but with limited (finite) power. Within the next simulation, it analyses all components of measured torque's courses that have been transformed regarding the power of the electric motor as follows:

- Transformed nominal torque (mean value) $200 \mathrm{Nm}$

- Transformed amplitude of dominant harmonic $150 \mathrm{Nm}$

- Auxiliary compensating PMSM motor has the same parameter rates as the traction PMSM simulating ICE engine.

All simulations have been provided in the Matlab/Simulink environment. The simulation model is shown in the next Figure 13. Regarding the stator voltage of PMSM, the calculations of the reference waveforms and their RMS values have been considered. 


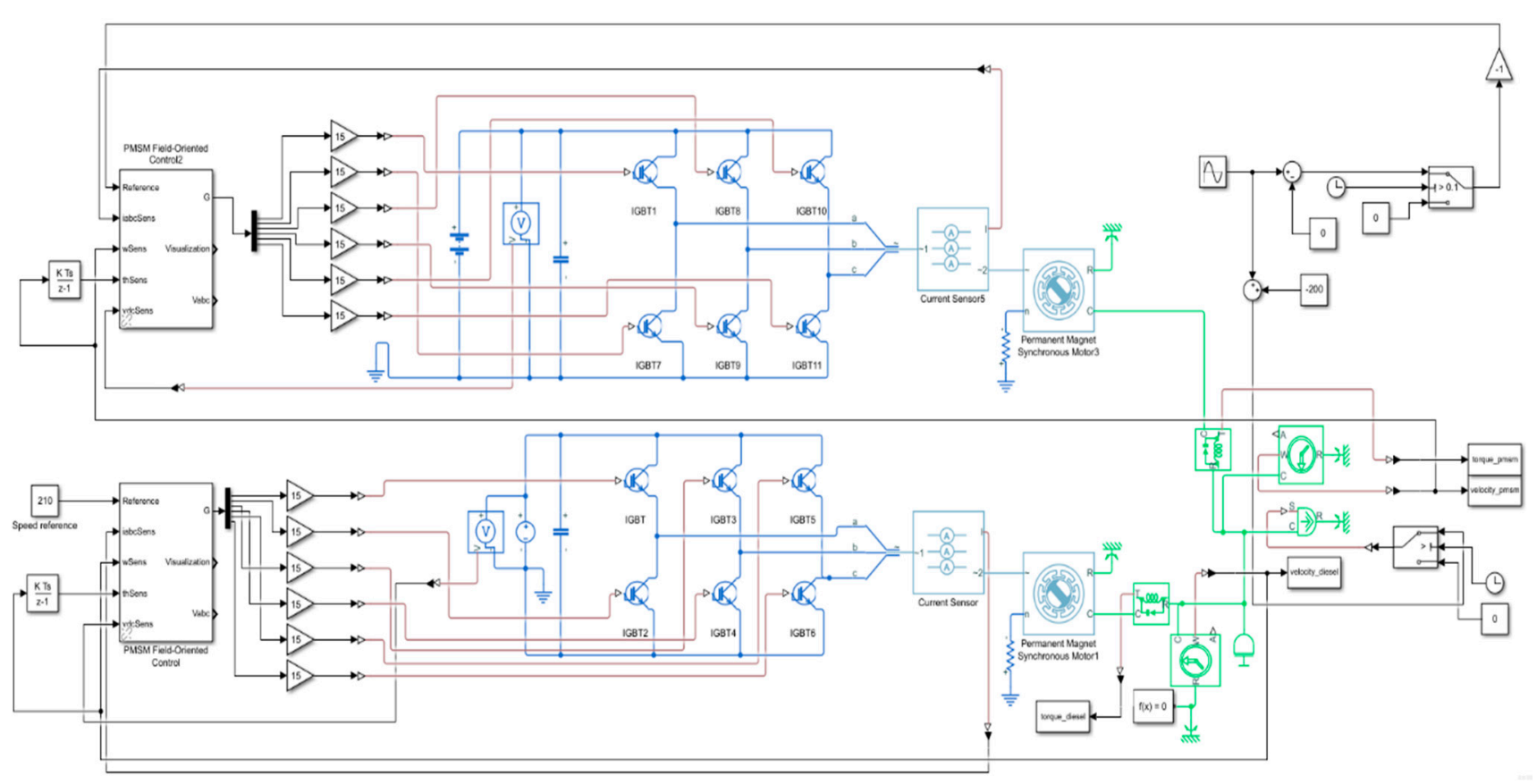

Figure 13. Simulation model in the Matlab/Simulink with two PMSM controlled by FOC (field-oriented control).

The simulation model in the Matlab/Simulink [20] comprises a model of both PMSM motors with FOC control. The presented concept is a parallel hybrid as it is shown in Appendix A, [13]. Using the $p-q$ theory, the power of fundamental harmonic is presented by average values Pav, Qav of total power waveforms $p(t)$, and $q(t)$.

\subsection{Operation Regime of PMSM for Compensation-\#R1}

Simulation results for the case when the electric motor is just compensating the oscillating torque of ICE are shown in Figures 14-16 (compensation switched on at $0.2 \mathrm{~s}$ ). Figure 14 shows the detailed waveform of angular speed, angular acceleration, and PMSM mechanical torque and torque of ICE, respectively. Until $0.2 \mathrm{~s}$, the PMSM motor does not produce any electromagnetic torque. The oscillation of the ICE angular speed (also PMSM) is not compensated. It is also shown in the angular acceleration waveform. After the time of load of the ICE engine was set to $200 \mathrm{Nm}$. In Figure 14 below is seen that the torque produced by the PMSM motor compensates the oscillating torque of the ICE. This operation is presented by the significant reduction of the angular speed ripple and angular acceleration ripple, respectively. The angular acceleration represents the overall vibration of the proposed drive. The PMSM active and reactive power component and their average values are shown in Figure 15. It is shown that the average value of the active power $P_{A V}$ is minimal due to not contributing the PMSM torque to the load. It contributes only to the compensation of the oscillating torque. The RMS value of the oscillating parts of $p, q$ components are shown in Figure 16. In this regime is seen that the PMSM motor must be designed to the peak value of $p$ component. 


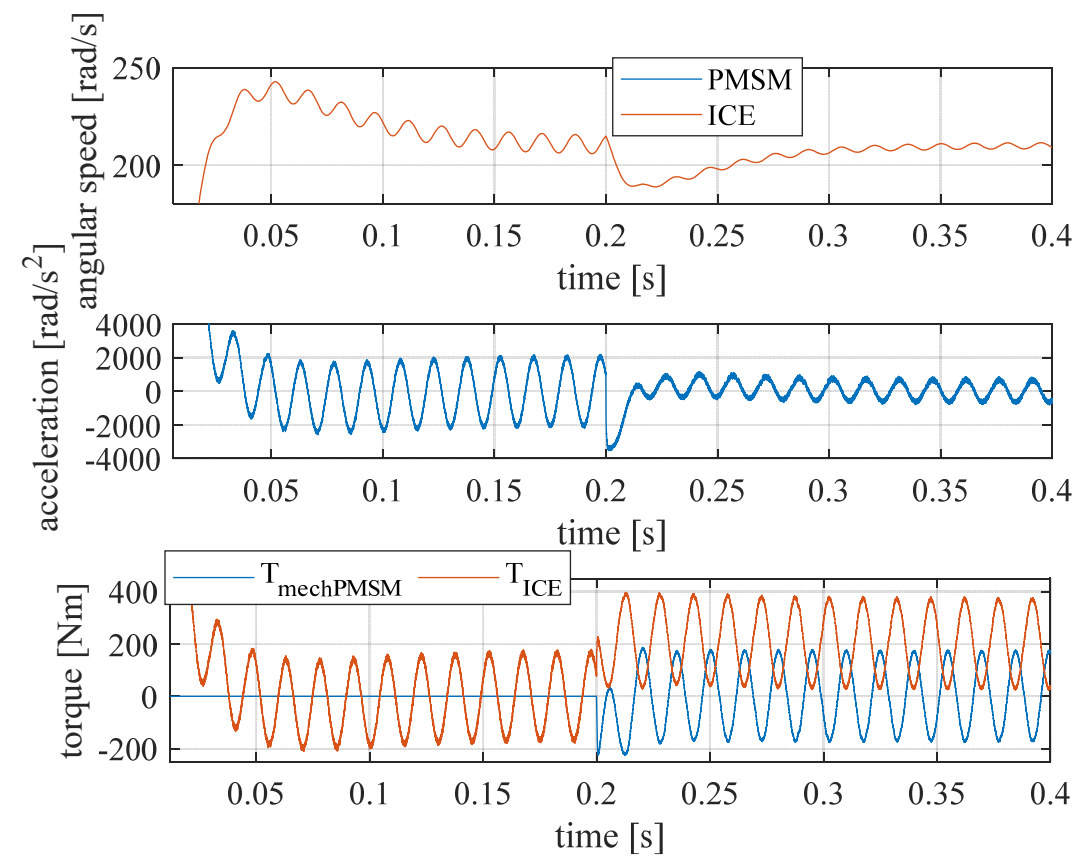

Figure 14. Speed, angular acceleration, and torques during compensation of ICE engine torque oscillations.
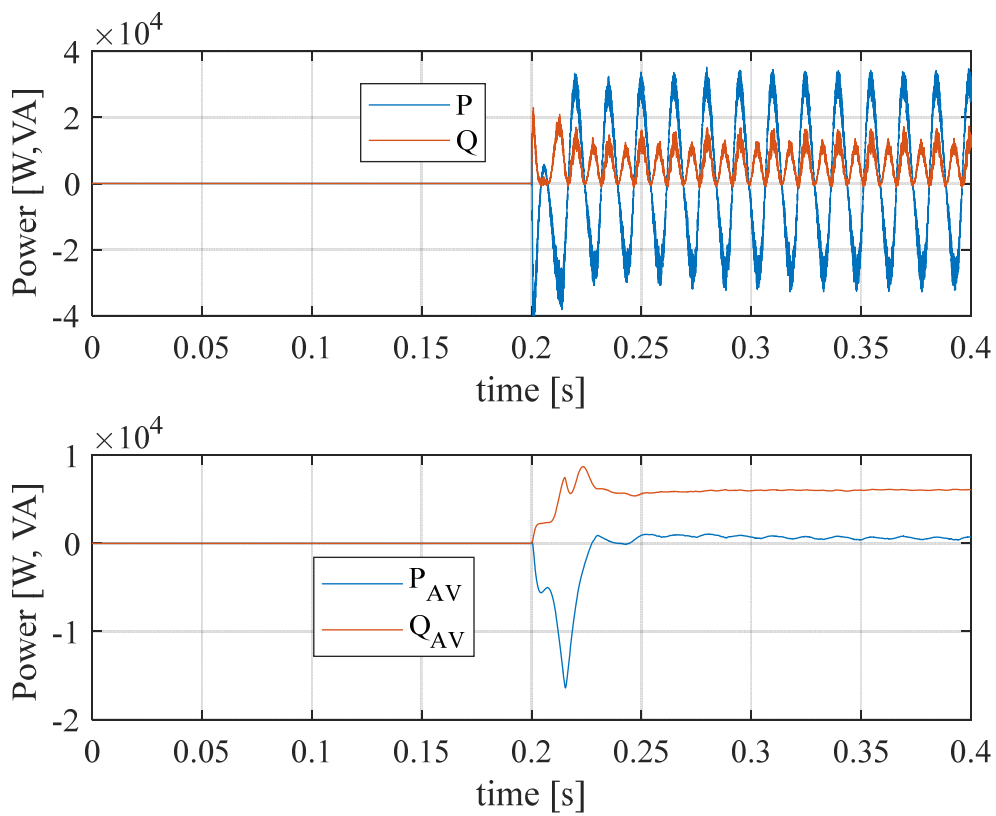

Figure 15. Active and reactive power during compensation of ICE engine torque oscillations. 

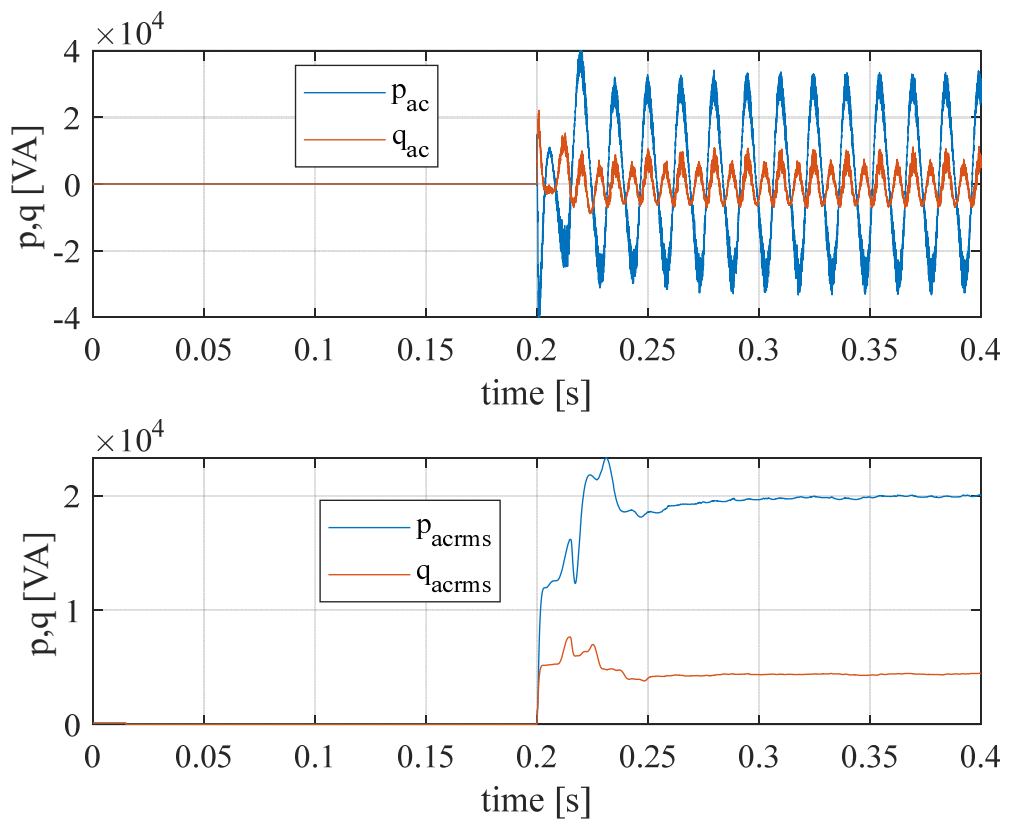

Figure 16. AC components of power during compensating of oscillating ICE engine torque.

Parameters:

- $\quad$ Nominal load torque $=200 \mathrm{Nm}$

- $\quad$ Oscillating torque amplitude $=150 \mathrm{Nm}$

- $\quad$ Frequency of oscillating $=85 \mathrm{~Hz}$

- $\quad$ Actual rotating speed $=210 \mathrm{rad} / \mathrm{s}$

- $\quad$ Apparent power $=21,334 \mathrm{VA}$

- Active power $=544 \mathrm{~W}$

- $\quad$ Power factor $\cos \varphi_{1}=0.088\left(\varphi_{1}=84^{\circ} \mathrm{el}\right.$.)

- $\quad P$-time waveform of the power in $p$-axis $\left(P_{A V}+p a c\right)$

- $Q$-time waveform of the power in $q$-axis $\left(Q_{A V}+q a c\right)$

- $P_{A V}$-average value of active power

- $Q_{A V}$-average value of reactive power

- $\quad p_{a c}$-ripple of the power in $p$-axis

- $q_{a c}$-ripple of the power in $q$-axis

- $\quad p_{a c r m s}$-rms of the power ripple in $p$-axis

- $q_{\text {acrms }}$-rms of the power ripple in $q$-axis

In this operating regime, the PMSM motor compensates for oscillating torque generated by the load. Waveforms of speed and torque of PMSM applied to the shaft have been interpreted together with power component waveforms (apparent, active, and reactive ones) on its input terminals. Note that compensation is provided mainly by reactive power.

\subsection{Operation Regime of PMSM for Parallel Cooperation with ICE — \#R2}

This case represents the operation of the ICE engine with a damping element. Therefore, the oscillating torque are compensated and only the cooperation of ICE and auxiliary PMSM machine as a booster machine are presented. Simulation results for the case when the e-motor and ICE motor cooperate in parallel are shown in Figures 17-19 (parallel cooperation at $0.2 \mathrm{~s}$ ). From Figure 17, it is seen that the oscillation in angular speed and angular acceleration are suppressed by the mechanical damping element. Therefore, the oscillating components of power $p, q$, and their rms values do not occur significantly in investigated waveforms (Figure 19), mainly in the transient state, when the parallel operation is applied. The main power is in this regime used to contribute power components $P_{A V}$ and $Q_{A V}$ to cover the load, Figure 18. 

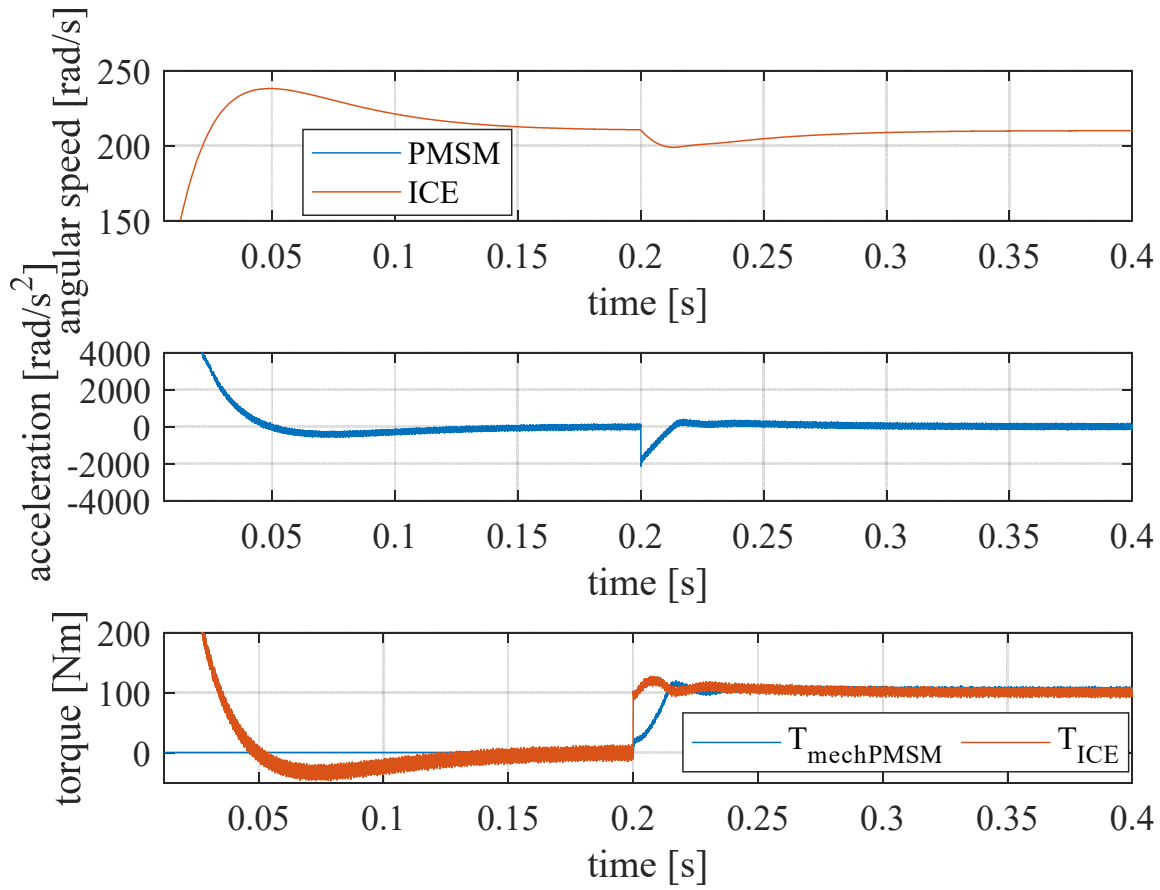

Figure 17. Speed and torques of parallel cooperating of both PMSM motor and ICE engine with damper.
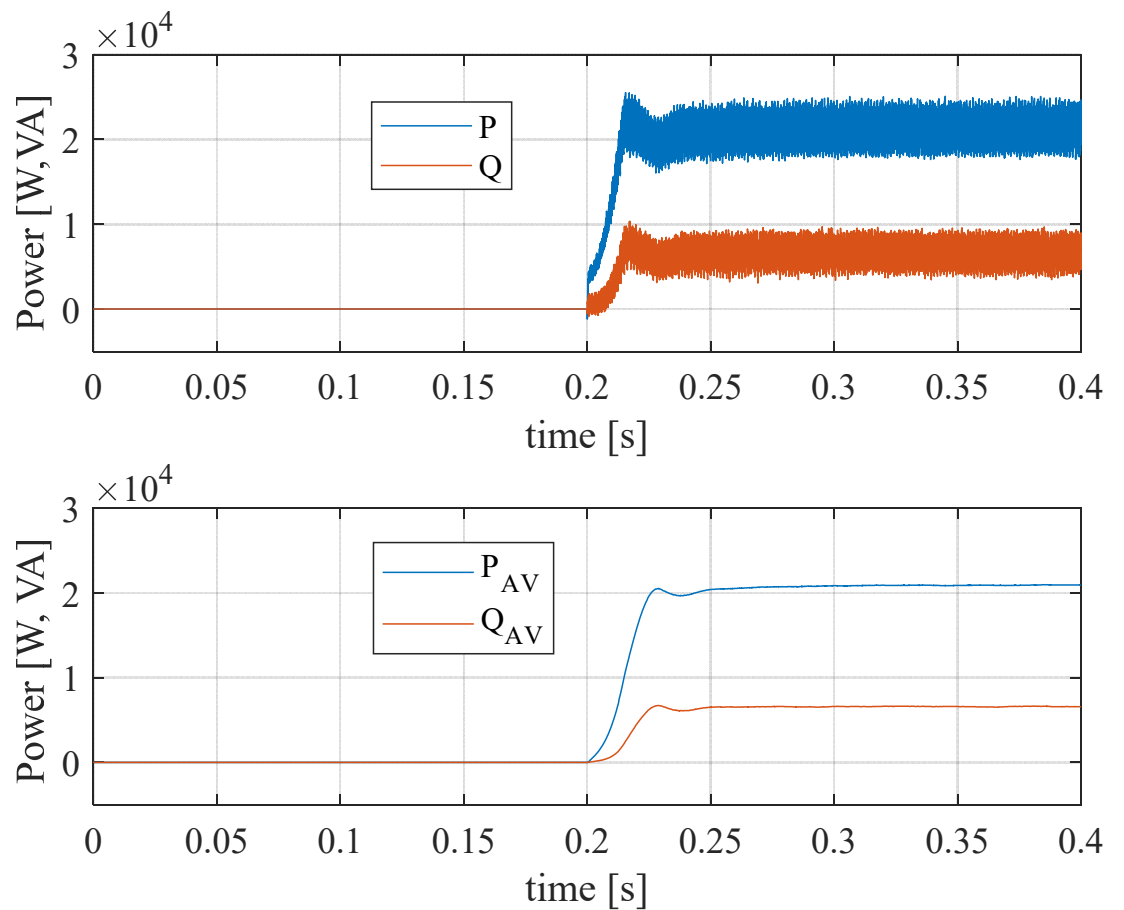

Figure 18. Active and reactive power during parallel cooperating of both PMSM motor and ICE engine with engine damper. 

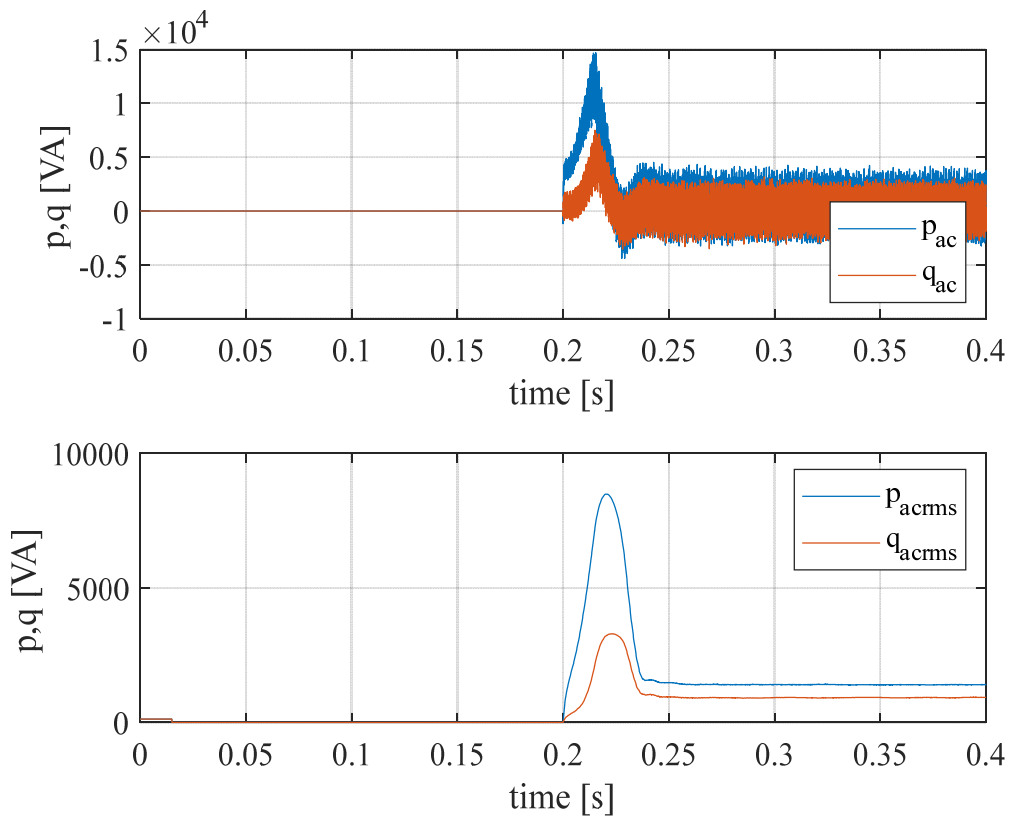

Figure 19. AC components of power during parallel cooperating of both PMSM motor and ICE engine with dumper.

Parameters:

- $\quad$ Nominal load torque $=200 \mathrm{Nm}$

- Elmagnetic torque $(\mathrm{PMSM})=100 \mathrm{Nm}$

- Mechanical torque (ICE) $=100 \mathrm{Nm}$

- $\quad$ Actual rotating speed $=210 \mathrm{rad} / \mathrm{s}$

- $\quad$ Apparent power $=21,889 \mathrm{VA}$

- $\quad$ Active power $=20,867 \mathrm{~W}$

- Power factor $\cos \varphi_{1}=0.95\left(\varphi_{1}=17^{\circ} \mathrm{el}\right.$. $)$

- $\quad P$-time waveform of the power in $p$-axis $\left(P_{A V}+p a c\right)$

- $Q$-time waveform of the power in $q$-axis $\left(Q_{A V}+q a c\right)$

- $P_{A V}$-average value of active power

- $Q_{A V}$-average value of reactive power

- $\quad p_{a c}$-ripple of the power in $p$-axis

- $\quad q_{a c}$-ripple of the power in $q$-axis

- $\quad p_{\text {acrms }}$-rms of the power ripple in $p$-axis

- $\quad q_{\text {acrms }}-\mathrm{rms}$ of the power ripple in $q$-axis

In this regime of operation, the PMSM motor delivers one-half (50\%) energy for the load torque. It is supposed that the torque generated by the ICE engine does not comprise the oscillating component due to ICE including a damper of rotating mass. Waveforms of speed and torque of PMSM on the shaft have been presented together with power components waveforms (apparent, active, and reactive ones) on its input terminals. Note that delivered power is provided by active power generated by PMSM.

\subsection{Operation Regime of PMSM for Oscillating Torque Compensation and Energy Recovery- \#R3}

Simulation results for the case when the ICE engine drives PMSG as a generator are shown in Figures 20-22 (PMSG switched on at $0.2 \mathrm{~s}$ ). In this regime of operation, the PMSM motor regenerates energy of the load to the battery via a VSI inverter. There are shown courses of speed, angular acceleration, and torque of PMSM on the shaft, power components waveforms (apparent, active, and reactive ones) on its input terminals. Note that delivered power presented mainly by $P_{A V}, Q_{A V}$ is negative one. This means that these 
components represent the power delivered back to the battery. The $p$ and $q$ component represent the power which is needed to compensate the oscillating torque.

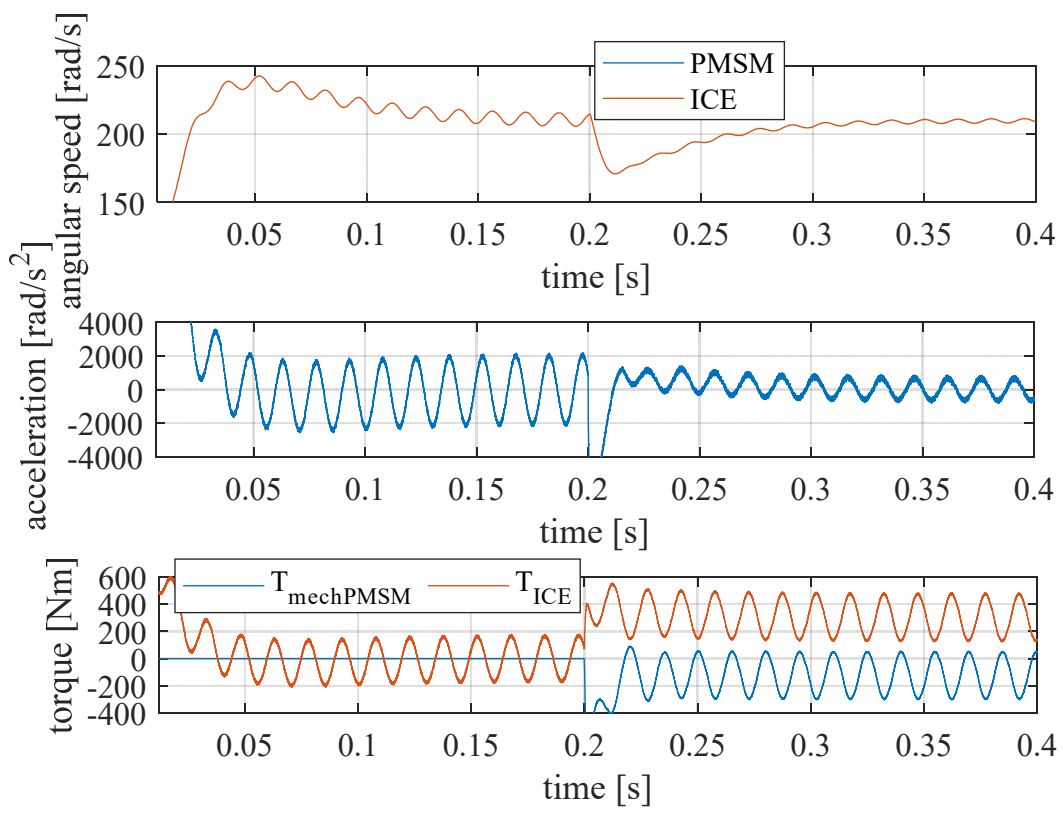

Figure 20. Speed, angular acceleration and torques when PMSM loaded ICE engine as generator.
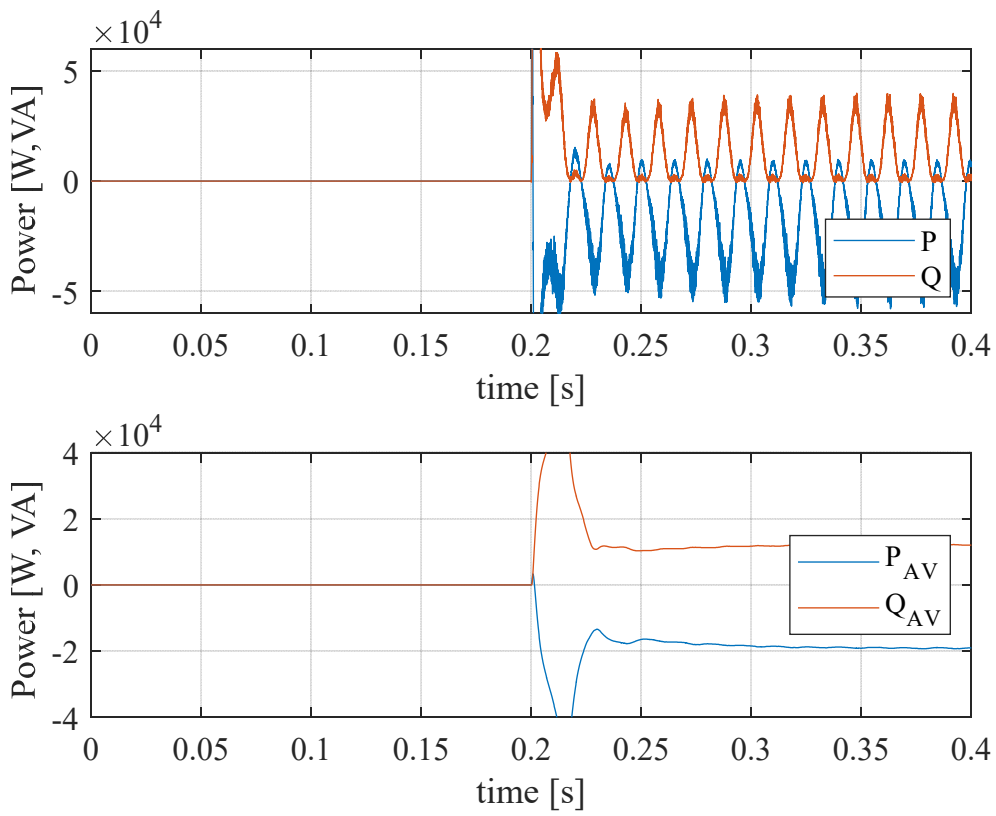

Figure 21. Active and reactive power when PMSM loaded ICE engine as the generator. 

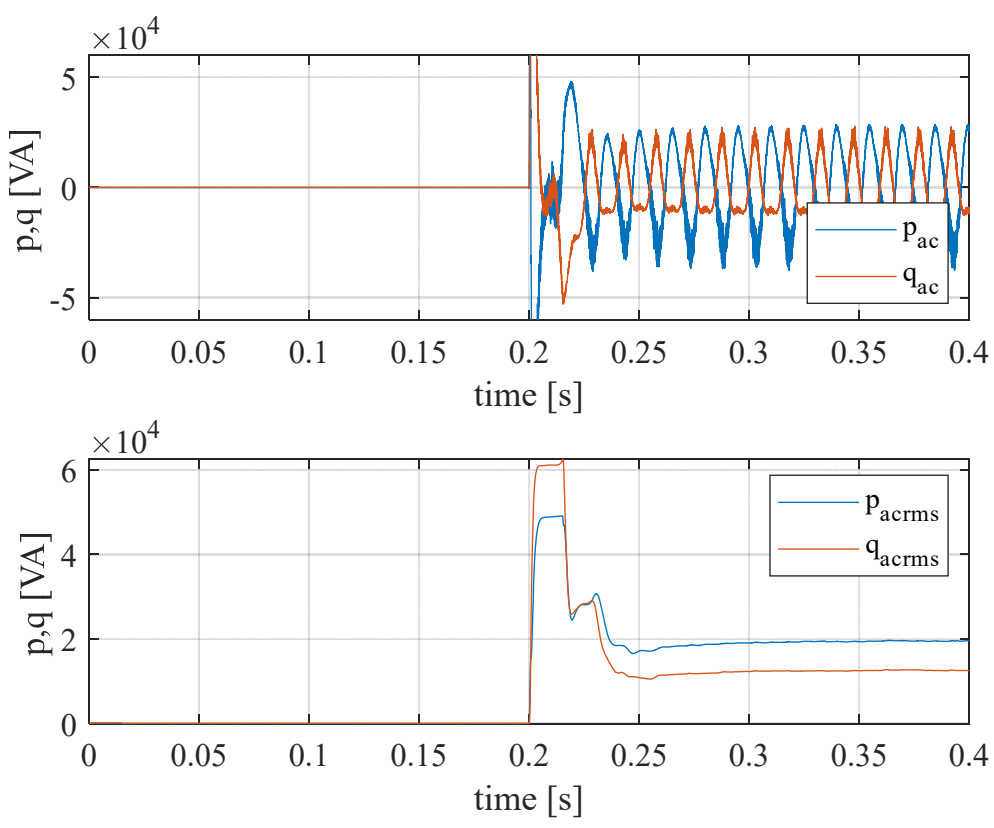

Figure 22. AC components of power when PMSM loaded ICE engine as the generator.

Parameters:

- $\quad$ Nominal load torque $=200 \mathrm{Nm}$

- Oscillating torque amplitude $=150 \mathrm{Nm}$

- Frequency of oscillating $=85 \mathrm{~Hz}$

- $\quad$ Actual rotating speed $=210 \mathrm{rad} / \mathrm{s}$

- $\quad$ Apparent power $=22,738 \mathrm{VA}$

- $\quad$ Active power regenerated $=19,189 \mathrm{~W}$

- $\quad P$-time waveform of the power in $p$-axis $\left(P_{A V}+p a c\right)$

- $Q$-time waveform of the power in $q$-axis $\left(Q_{A V}+q a c\right)$

- $P_{A V}$-average value of active power

- $Q_{A V}$-average value of reactive power

- $\quad p_{a c}$-ripple of the power in $p$-axis

- $\quad q_{a c}$-ripple of the power in $q$-axis

- $\quad p_{\text {acrms }}-\mathrm{rms}$ of the power ripple in $p$-axis

- $q_{\text {acrms }}$-rms of the power ripple in $q$-axis

\subsection{Operation Regime of PMSM for Compensation and Parallel Cooperation with ICE-\#R4}

Simulation results of compensation and parallel cooperation of ICE engine and PMSM motor are shown in Figures 23-25 (compensation and cooperation switched on at $0.2 \mathrm{~s}$ ).

In this regime of operation, the PMSM motor delivered one-half (50\%) energy for the load torque, and at the same time, it compensated the oscillating component of the torque. Waveforms of speed, acceleration, and torque of PMSM on the shaft are being shown together with power components waveforms (apparent, active, and reactive ones) on its input terminals. Using $p-q$ theory, the power of fundamental harmonic is presented by average values Pav, Qav of total power waveforms $p(t)$ and $q(t)$. From Figure 23, it is shown that angular speed and acceleration ripple is reduced as in other regimes. The amplitude of the angular acceleration/vibration was before compensation $2000 \mathrm{rad} / \mathrm{s}^{2}$. After compensation, the value is reduced to $500 \mathrm{rad} / \mathrm{s}^{2}$. It is shown that the mean torque value is equally divided between the ICE and PMSM. The oscillating torque component is also reduced. From Figure 24, it is seen the $P, Q$ component and their average values $P_{A V}, Q_{A V}$. It is evident that the active power is increased due to contributing to the load torque. The $p, q$ component and their RMS values are shown in Figure 26, which represent 
power components of the oscillation. Then, $P_{A V}$ and $Q_{A V}$ are positive ones and represent the power that are utilized to contribute to the load torque. Therefore, the motor must be designed to sum $P_{A V}$ and $p_{a c}$ values.

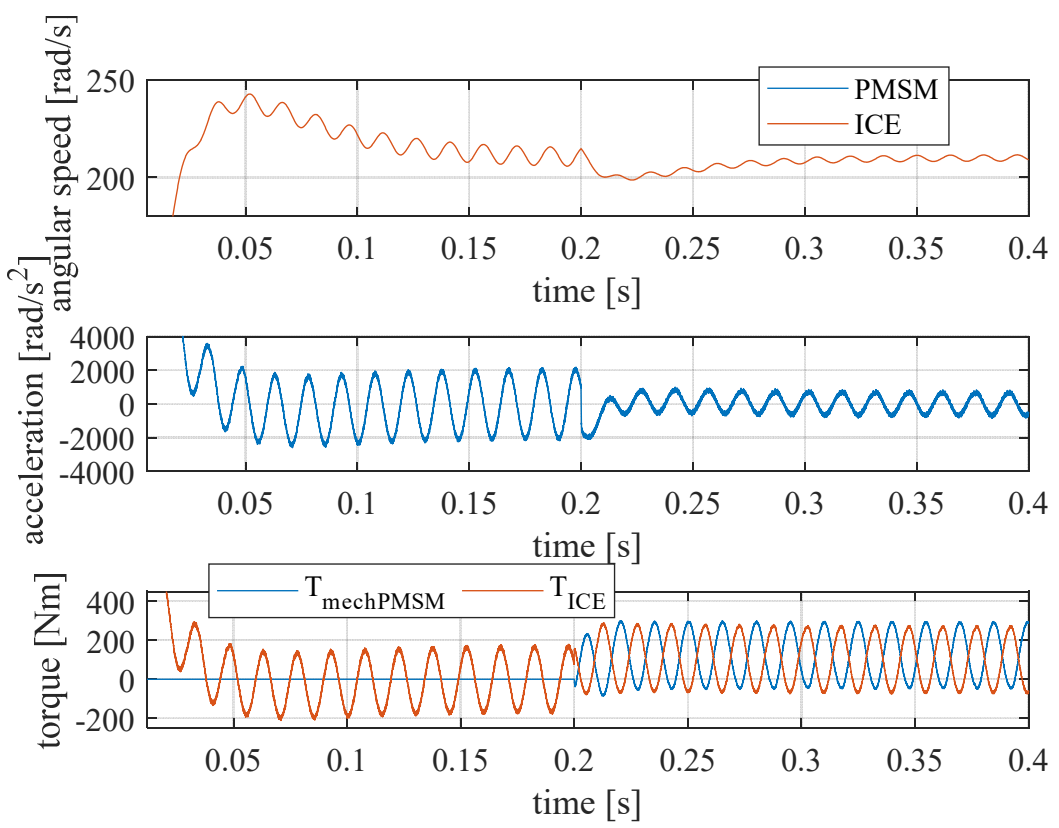

Figure 23. Speed and torques during parallel cooperation and compensation oscillating torques.
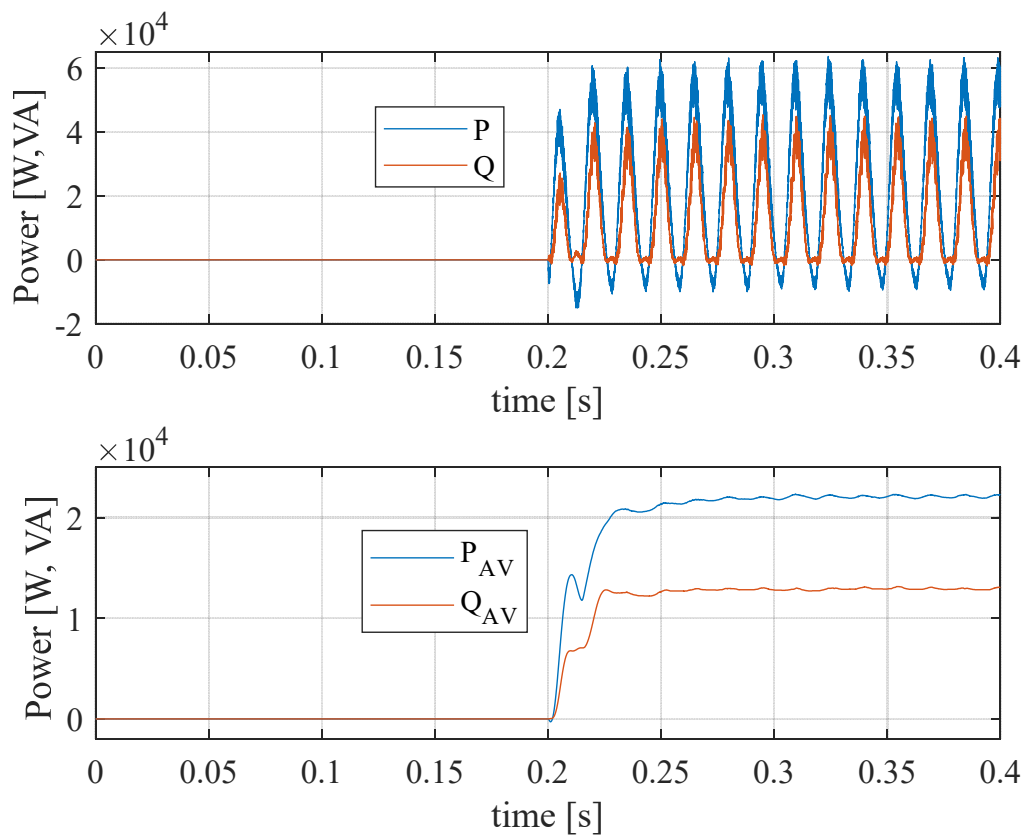

Figure 24. Active and reactive power during parallel cooperation and compensation oscillating torques. 

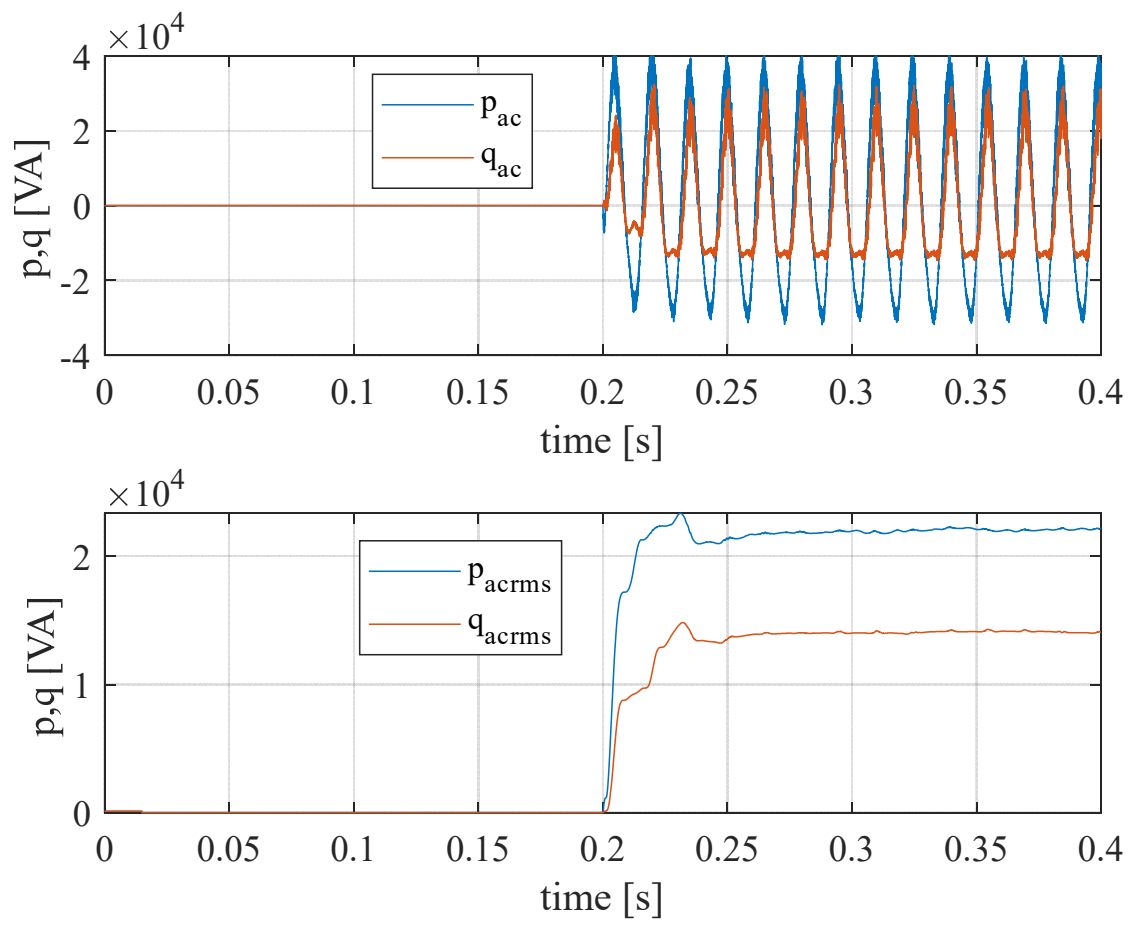

Figure 25. AC components of power during parallel cooperation and compensation oscillating torques.

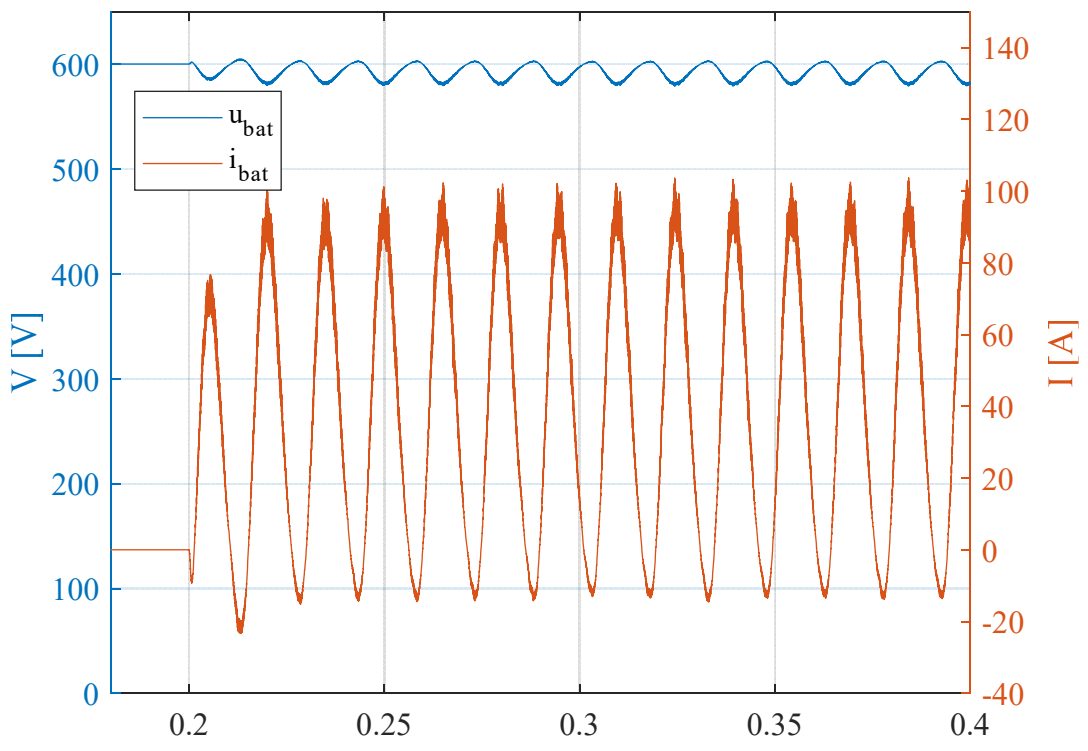

Figure 26. Time waveforms of battery voltage and current.

Parameters:

- $\quad$ Nominal load torque $=200 \mathrm{Nm}$

- Oscillating torque amplitude $=150 \mathrm{Nm}$

- $\quad$ Frequency of oscillating $=85 \mathrm{~Hz}$

- $\quad$ Actual rotating speed $=210 \mathrm{rad} / \mathrm{s}$

- $\quad$ Apparent power $=36,558 \mathrm{VA}$

- $\quad$ Active power $=22,037 \mathrm{~W}$

- $\quad$ Power factor $\cos \varphi_{1}=0.86\left(\varphi_{1}=30^{\circ} \mathrm{el}\right.$.)

- $\quad P$-time waveform of the power in $p$-axis $\left(P_{A V}+p a c\right)$

- $Q$-time waveform of the power in $q$-axis $\left(Q_{A V}+q a c\right)$ 
- $\quad P_{A V}$-average value of active power

- $Q_{A V}$-average value of reactive power

- $\quad p_{a c}$-ripple of the power in $p$-axis

- $\quad q_{a c}$-ripple of the power in $q$-axis

- $\quad p_{\text {acrms }}$-rms of the power ripple in $p$-axis

- $\quad q_{\text {acrms }}$-rms of the power ripple in $q$-axis

Note that besides parallel cooperation the oscillating component of the torque is compensated by the electromagnetic torque of PMSM. The battery current and voltage is shown in Figure 26. The current from the battery is the mean value of the total current flowing from the DC-bus. The higher frequency component of the current is taken from the DC-bus capacitors, which is shown in Figure 27. At this point, a new technical problem arises with the selection of a suitable battery and DC-bus capacitor pack, which is not the topic of this article.

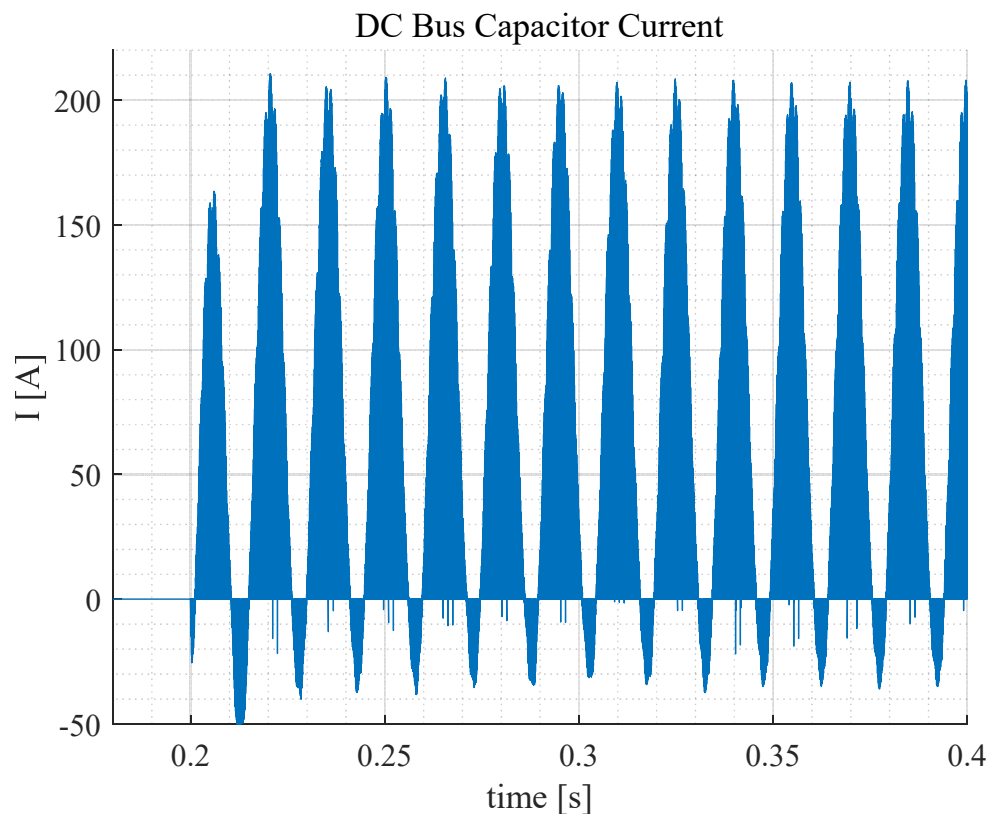

Figure 27. Time waveforms of DC-bus capacitor current.

Thereby, the active power taken from the accu-battery

- $\quad P_{\mathrm{AB}}=22,9 \mathrm{~kW}$

- $U_{\mathrm{ABnom}}=600 \mathrm{~V}$

- $I_{\mathrm{ABav}}=38.2 \mathrm{~A}$

- $I_{\mathrm{ABpk}-\mathrm{pk}}=105 \mathrm{App}$ will be:

Therefore, the consumption of electric energy taken from traction accumulator battery

$$
\left(P_{A B}\right)_{a v}=\frac{1}{T} \int_{0}^{T} u_{A B} i_{A B} \mathrm{~d} t
$$

The power taken from the battery $P_{(A B) a v}$ corresponds to the $P_{A V}$ power component in \#R4. Therefore, the selection/design of the battery depends on the fluctuation current $I_{A B p k-p k}$ and mean power $P_{A V}$ of the PMSM.

\section{Discussion about Potential Application in Parallel HEV Powertrain}

In all 4 regimes \#R1, \#R2, \#R3 and \#R4 the power of the machine depends on the $P$ power component. In a state where only the compensation of oscillating torque is provided, the $p_{a c}$ component is mandatory to PMSM selection. On the other hand, in a cooperation mode, the mean value of active power $P_{A V}$ is decisive. 
At first, it is evident that the speed and torque ripple of the HEV shaft has been significantly reduced due to compensation of non-active oscillating torque as can be seen in Figures 14, 20 and 23 (from 5\% to 1\% in case of speed ripple and from 95\% to $23 \%$ in case of torque ripple).

Further, worked-out simulation results. shown in Figures 14-26 have shown all parameters needed to determine the dimension of auxiliary traction PMSM motor, power supply VSI converter, and the amount of consumption of electric energy drawn from traction accumulation battery. The four operation regimes based on real torque data were investigated:

In \#R1, the auxiliary electric motor compensates the oscillating torque. Figure 15 shows that the mean value of active power $P_{A V}$ is minimal. It covers "only mechanical and electrical losses" in the motor. The value is about $700 \mathrm{~W}$. The value of reactive power component $Q_{A V}$ is 6075 Var. The distortion power calculating according to Equation (38) and data from Figure 16 is 20,444 Var. Then the apparent power is calculated according to Equation (39) and its value is 21,334 VA with $\cos \phi 0.116$.

In \#R2, the oscillating torque is compensated using the rotating mass in an ICE engine. Therefore, the estimated torque is without an AC component. In this regime, the electric motor delivers mainly the active power $P_{A V}=20.87 \mathrm{~kW}$, which is $50 \%$ of total active power and its value is shown in Figure 18. The value of $\cos \phi=0.95$ is calculated as the division of active and apparent power.

In \#R3 regime, the compensation of the oscillating torque component and energy recovery of the auxiliary electric motor is shown. This regime loaded an ICE engine by the value of the regenerating power. The value of regenerating power $P_{A V}$ is $-19,189 \mathrm{~W}$, and it is shown in Figure 21.

In \#R4, the apparent power calculated according to Equation (39) is $36,558 \mathrm{VA}$. The power is divided into two parts. For the compensation of oscillating torque, which is shown in Figure 25, and for parallel cooperation, shown in Figure 24. In this regime, maximal power transmitted by PMSM motor and VSI converter reaches more value than ICE mechanical power (about $20 \mathrm{~kW}=200 \mathrm{rad} / \mathrm{s} \times 100 \mathrm{Nm}$ ).

The power drawn from the battery is equal to the mean value of power $P_{A V}$ intended for parallel cooperation. The oscillating component of the current does not increase the need for more battery power, because in a half period, the power is delivered and in the second half, the power is recovered. Thereby, the active power taken from the battery is just $22.9 \mathrm{~kW}$. But the auxiliary PMSM motor and VSI inverter should be sized to that apparent value of power.

\section{Conclusions}

In this paper, the research issues related to the determination of the active damping of non-active torques of parallel HEV were investigated. The presented approach is based on the real measured data, which have been received from the manufacturer of car flywheels. The variables of the internal combustion engine have been analyzed and consequently, an active damping system was proposed to investigate the possibilities and sizing of the auxiliary electrical PMSM motor or IM motor for active dumping purposes. The investigations are based on the simulation modeling, which enables to research the relevant dependencies according to compensation torque, current, and the way of the control of the auxiliary electrical machine. Here, four modes have been analyzed separately, i.e., compensation of non-active torques, parallel operation, regeneration of PMSM and parallel operation with compensation. The $p-q$ theory was implemented within the control algorithm; these average values have been controlled of the total power waveforms $(p(t)$ and $q(t))$. The contribution of the paper is suitable if proper sizing and dimensioning of the auxiliary electrical machine, relevant power electronic system, and traction battery are required. 
Author Contributions: B.D.: conceptualization, writing-original draft preparation, investigation. S.K.: conceptualization, software, validation, writing-review and editing. M.F.: formal analysis, supervision, funding acquisition. M.P.: visualization, data curation, project administration. All authors have read and agreed to the published version of the manuscript.

Funding: This publication was realized with the support of the Operational Program Integrated Infrastructure 2014-2020 of the project: Innovative Solutions for Propulsion, Power and Safety Components of Transport Vehicles, code ITMS 313011V334, and co-financed by the European Regional Development Fund.

Conflicts of Interest: The authors declare no conflict of interest.

\section{Nomenclature}

$T_{a v}$-average torque

$T_{a v, n o m}-$ nominal value of average torque

$T_{\text {osc }}$-oscillating torque

$t_{\text {osc }}$-time waveform of oscillating torque

$T_{p k-p k}$-torque ripple

$t_{\text {elmg }}$-electromagnetic torque

$T_{l}$-load torque

$t_{l}$-actual torque

$t_{a c c}$-accelerating torque

$J_{m}$-motor moment of inertia

$\omega_{m}$-angular speed

$t_{\text {fri }}$-friction (torque)

$t_{l, e s t}$-estimated torque

$i_{m}$-stator current

$u_{d}$-voltage in $d$-axis

$i_{d}$-current in $d$-axis

$R_{S}$-stator resistance

$U_{a, r m s}, U_{b, r m s}, U_{c, r m s}$-effective values of phase voltage

$I_{a, r m s}, I_{b, r m s}, I_{c, r m s}$-effective values of phase currents

$I_{\alpha, r m s}, I_{\beta, r m s}$-effective values of currents in $\alpha \beta$ coordinates $\varphi_{1}$-phase angle between first harmonics of voltage and current

$P_{1(a v)}$ - mean value of the active power

$L_{d}$-inductance in $d$-axis

$L_{q}$-inductance in $q$-axis

$u_{q}$-voltage in $q$-axis

$i_{q}$-current in $d$-axis

$\Psi_{P M}$-flux of PM

$P p$-number of pole pairs

$\vartheta_{m}$-rotor position

$\tau_{\text {mech }}$-mechanical time constant

HEV—hybrid electric vehicle

PMSM - permanent magnet synchronous motor

IM-induction motor

ICE-internal combustion engine $i_{s \alpha}, i_{s \beta}$-stator currents in $\alpha, \beta$-axes

$i_{a}, i_{b}, i_{c}$-phase currents

$a_{k}, b_{k}, c_{k}$-members of Fourier series

$Q_{\Sigma}$-reactive power of all harmonic components

$D_{\Sigma}$-distortion power of all harmonic components

$i_{r \alpha} \cdot i_{r \beta}$-rotor currents in $\alpha, \beta$-axes

$\mathrm{L}_{\mathrm{m}}$-mutual inductance

$\Delta \mathrm{T}$-sampling period

$\mathrm{K}_{\mathrm{r}}, \mathrm{K}_{\mathrm{s}}$-Blondel's coefficients

$\mathrm{L}_{\mathrm{S}}, \mathrm{L}_{\mathrm{r}}$-stator and rotor inductance

$\mathrm{R}_{\mathrm{r}}$-rotor resistance

$a_{k}, b_{k}, c_{k}$-Fourier coefficients

kwtk-angular frequency

$\mathrm{T}_{\text {tot }}$-total torque

$\mathrm{P}_{1 \text { (av) }}$-active power on the shaft

p_q-reactive power theory

$\mathrm{U}_{1 \mathrm{rms}}, \mathrm{I}_{1 \mathrm{rms}}$-fundamental rms values

$I_{\Sigma, r m s}$ - sum of effective values of higher current harmonics

$U_{\Sigma, r m s}$ - sum of effective values of higher voltage harmonics

$I_{k, r m s}$ - effective value of kth harmonic

$I_{\Sigma p, r m s}, I_{\Sigma q, r m s}$-effective values of currents in p-q axis

$U_{\alpha, r m s}, U_{\beta, r m s}$-effective values of voltages in $\alpha \beta$ coordinates

$\mathrm{Q}_{1(\mathrm{av})}$-reactive power of fundamental

$\varphi_{1}$-phase shift fundamental

$\mathrm{D}_{\mathrm{av}}$ - distortion power

$\mathrm{S}_{\mathrm{av}}$-apparent power

$\mathrm{p}, \mathrm{q}$-actual total power in $\mathrm{p}$, q-axis

$\mathrm{p}_{\mathrm{ac}} \mathrm{q}_{\mathrm{ac}}$-distortion parts of power

$\mathrm{P}_{\mathrm{AV}}, \mathrm{Q}_{\mathrm{AV}}-$ mean value of active and reactive power

$P_{\mathrm{ac}, \mathrm{rms}}, \mathrm{Q}_{\mathrm{ac}, \mathrm{rms}}-\mathrm{rms}$ value of powers

VSI-voltage source inverter

FOC-field-oriented control

MAM-moving average method

MATLAB - matrix laboratory environment of MathWorks, Inc 


\section{Appendix A}

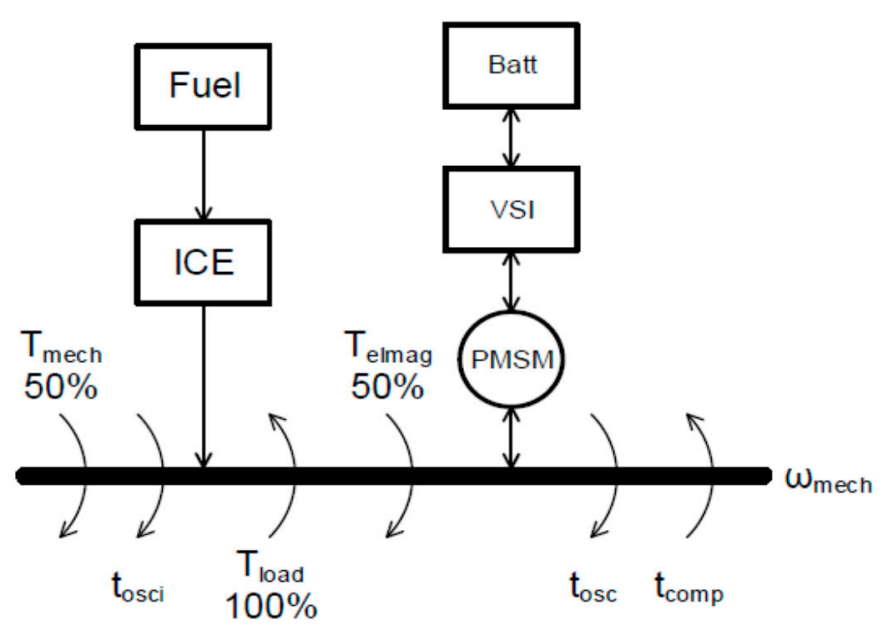

Figure A1. Arrangement of cooperating ICE engine and PMSM motor in the parallel HEV vehicle.

\section{References}

1. Suntharalingam, P.; Yang, Y.; Jiang, W. Chap. 12 Hybrid Electric Vehicles. In Advanced Electrical Drive Vehicle; (e-book); Emadi, A., Ed.; CRC Press, Taylor \& Francis Group: Boca Raton, FL, USA, 2015.

2. Böhme, T.J.; Frank, B. Hybrid Systems, Optimal Control and Hybrid Vehicles. Adv. Ind. Control 2017, 79-115. [CrossRef]

3. Pimkumwong, N.; Wang, M.S. Online Speed Estimation Using Artificial Neural Network for Speed Sensorless Direct Torque Control of Induction Motor based on Constant V/F Control Technique. Energies 2018, 11, 2176. [CrossRef]

4. Qian, W.Z.; Panda, S.K.; Xu, J.-X. Torque ripple minimization in PM synchronous motors using iterative learning control. IEEE Trans. Power Electron. 2004, 19, 272-279. [CrossRef]

5. Stefun, R. Application of Recursive-Iterative Identification Methods for Power Converters. Ph.D. Thesis, University of Zilina, Žilina, Slovakia, August 2020.

6. Piccoli, M.; Yim, M. Torque ripple suppression, modeling, and parameter selection. Int. J. Robot. Res. 2016, 35, 148-160. [CrossRef]

7. Hanselman, D. Brushless Permanent Magnet Motor Design, 2nd ed.; Magna Physics Publishing: Lebanon, OH, USA, 2006.

8. Hanselman, D. Minimum Torque Ripple, Maximum Efficiency Excitation of Brushless Permanent Magnet Motors. IEEE Trans. Ind. Electron. 1994, 41, 292-300. [CrossRef]

9. Park, H.W.; Park, S.J.; Lee, Y.W.; Song, S.; Kim, C. Reference frame approach for torque ripple minimization of BLDCM over wide speed range including cogging torque. IEEE Trans. Ind. Electron. 2000, 47, 637-642.

10. Springob, L.; Holtz, J. High-Bandwidth Current Control for Torque-Ripple Compensation in PM Synchronous Machines. IEEE Trans. Ind. Electron. 1998, 45, 713-721. [CrossRef]

11. Bowling, D.; Starr, G.; Wood, J.; Lumia, R. Wide Band Suppression of Motion-Induced Vibration. In Proceedings of the 2007 IEEE International Conference on Robotics and Automation, Roma, Italy, 10-14 April 2007; pp. 4530-4536.

12. Mattavelli, P.; Tubina, L.; Zigliotto, M. Torque-Ripple Reduction in PM Synchronous Motor Drives Using Repetitive Current Control. IEEE Trans. Power Electron. 2005, 20, 1423-1431. [CrossRef]

13. Qin, Y.; Tang, X.; Jia, T.; Duan, Z.; Zhang, J.; Li, Y.; Zheng, L. Noise and vibration suppression in hybrid electric vehicles: State of the art and challenges. Renew. Sustain. Energy Rev. 2020, 124, 109782. [CrossRef]

14. Tang, X.; Hu, X.; Yang, W.; Yu, H. Novel Torsional Vibration Modeling and Assessment of a Power-Split Hybrid Electric Vehicle Equipped with a Dual-Mass Flywheel. IEEE Trans. Veh. Technol. 2018, 67, 1990-2000. [CrossRef]

15. Akagi, H.; Kanazawa, Y.; Nabae, A. Generalized theory of the instantaneous reactive power in three-phase circuits. In Proceedings of the IPEC Conference, Tokyo, Japan, July/August 1983; pp. 1375-1386.

16. Herrera, R.S.; Salmerón, P. Instantaneous Reactive Power Theory: A Reference in the Nonlinear Loads Compensation. IEEE Trans. Ind. Electron. 2009, 56, 2015-2022. [CrossRef]

17. Caruso, M.; Di Tommaso, A.O.; Lisciandrello, G.; Mastromauro, R.A.; Miceli, R.; Nevoloso, C.; Spataro, C.; Trapanese, M. A General and Accurate Measurement Procedure for the Detection of Power Losses Variations in Permanent Magnet Synchronous Motor Drives. Energies 2020, 13, 5770. [CrossRef]

18. Hwang, M.H.; Lee, H.-S.; Cha, H.R. Analysis of Torque Ripple and Cogging Torque Reduction in Electric Vehicle Traction Platform Applying Rotor Notched Design. Energies 2018, 11, 3053. [CrossRef]

19. Frivaldsky, M.; Dobrucky, B.; Kascak, S. Research of Possibilities of HEV Oscillating Torque Compensation. In Research Interim Report of Department of Mechatronics and Electronics; University of Zilina: Zilina, Slovakia, 2019.

20. Murphy, J.M.D.; Turnbull, F.G. Power Electronic Control of AC Motors; Pergamon Press: Oxford, UK, 1989; ISBN 0-08-022683-3.

21. Zaskalicky, P. Steady state analysis of a two-phase PMSM supplied by a PWM controlled inverter. Acta Tech. 2013, 58, 83-89. 
22. Malek, M.; Makys, P.; Stulrajter, M. Control of Electrical Drives; EDIS Publishing House of the University of Zilina: Zilina, Slovakia, 2017; ISBN 978-80-554-1334-1. (In Slovak)

23. Sumega, M.; Rafajdus, P.; Stulrajter, M. Current Harmonics Controller for Reduction of Acoustic Noise, Vibrations and Torque Ripple Caused by Cogging Torque in PM Motors under FOC Operation. Energies 2020, 13, 2534. [CrossRef]

24. MathWorks Inc. Matlab/Simulink; R2020a Version; MathWorks Inc.: Natick, MA, USA, 2020. 